\title{
Determination of the effective geometrical features of the piercing punch for polymer composite belts
}

\author{
Dominik Wojtkowiak $^{1} \cdot$ Krzysztof Talaśka $^{1}$
}

Received: 21 December 2018 / Accepted: 14 April 2019 / Published online: 31 May 2019

(C) The Author(s) 2019

\begin{abstract}
Punch optimization is important in improving the technological process of belt perforation. Research about this process can rarely be found in the scientific literature. The objective of this paper is to determine the effective geometry of the piercing punches with a spherical bowl used for polymer composite belts. In order to fulfill this goal, the complex research of the influence of the geometrical features of the piercing punch on the perforation force, the hole quality, and the tool life has been conducted. For derivation of the proposed model, the authors have used the combination of analytical and FEM analyses, along with the experimental tests validation. Based on the results, there are clear correlations between the depth of the spherical bowl punch and the perforation force or the hole diameter deviation. By analyzing the ratio of the perforation and transverse force, we are able to evaluate how the tool life will change for different sets of geometrical parameters. All these correlations have been used to derive the indicators of the perforation force, tool life, and hole quality. Based on those, the optimization function has been specified. Finding the minimum value of this function makes it possible to define the optimal tool geometry. The design of effective tools for belt perforation with diameters $D=5,6,8$, and $10 \mathrm{~mm}$ has been presented, but the obtained characteristic makes it possible to find an optimal solution for any diameter which lays in the range from 3 to $10 \mathrm{~mm}$. Since the model has been built based on the indicators, it is easy to adjust it to match any specific requirements of the belt manufacturers, which makes it useful for tool designers.
\end{abstract}

Keywords Belt perforation $\cdot$ Punching $\cdot$ Tool optimization $\cdot$ Polymer composites

\section{Nomenclature}

$\Delta \quad$ Hole diameter deviation

$\delta \quad$ Ovality factor

$\mu \quad$ Friction coefficient

A Area of transverse compression

$D \quad$ Diameter of a piercing punch

$D_{L} \quad$ Hole diameter in longitudinal direction

$D_{N} \quad$ Nominal diameter of the hole

$D_{T} \quad$ Hole diameter in transverse direction

$E \quad$ Young's modulus

$F_{F} \quad$ Inside surface of the spherical bowl friction

$F_{F O} \quad$ Side surface of the piercing punch fricition

$F_{i} \quad$ Force of the spring in the point $i$

$F_{M} \quad$ Resistance force of the material

$F_{R} \quad$ Radial force
$F_{P} \quad$ Perforation force

$F_{T} \quad$ Transverse force

$H \quad$ Depth of a spherical bowl

Depth of the penetration

Constant of the spring in the point $i$

Clearance between a punch and a die

Length of the undeformed material

Number of points on the penetration length

$p_{T} \quad$ Transverse punch-belt pressure

$p_{V} \quad$ Vertical punch-belt pressure

$R \quad$ Radius of a spherical bowl

$r \quad$ Radius of the cutting edge

$x$

$x_{F}$

$x_{L}$

$x_{Q}$
Width of the ring of the punch

Perforation force indicator

Tool life indicator

Hole quality indicator
$N$

$N$

$m m$

$m m$

$N / m m$

$\mathrm{mm}$

$m m$

$-$

$M P a$

$M P a$

$m m$

$m m$

$\mathrm{mm}$

-

$-$

Dominik Wojtkowiak

dominik.wojtkowiak@put.poznan.pl

\section{Introduction}

1 Chair of Basics of Machine Design, Poznan University of Technology, ul. Piotrowo 3, 60-965 Poznań, Poland

Perforation of the conveyor belts, due to the variety of materials used for manufacturing multilayer composite belts and 
the range of their mechanical properties, became a serious issue for manufacturers worldwide. Conventional tools are no longer suitable for the punching process, considering its efficiency, durability, and quality of the holes. Wojtkowiak et al. [1] stated that using the non-mechanical modern methods, like laser cutting or abrasive water jet (AWJ), is limited due to the heat influence or generates very high costs. This indicates that the simplest mechanical method of belt perforation-punching with two cutting edges (a piercing punch which cooperates with a die)-may be considered as an optimal one, if the effective geometry of the piercing punch will be determined. Based on the previous research presented in [2], the concave piercing punches, especially the one with spherical bowl, may greatly reduce the perforation force.

According to Talaśka and Wojtkowiak [3], polymer composite belts may be divided into three groups: elastic light belts reinforced with fabrics, rigid belts with increased strength with thick films as their cores, and durable flexible belts reinforced with cords. The structure of the belts may be either multilayer or fibre-reinforced. Among the materials of which separate layers are made of most common are polyamide, polyester, polyurethane, rubber, PVC, and aramid or carbon fibers. The main focus in the presented research is put on the rigid belts with increased strength whose core is made of polyamide film covered by polyamide fabric protective gaskets and nitrile rubber (NBR) covers. According to the previous research presented in [4], this type of belts needs the highest perforation force and the quality of the hole strictly depends on the geometry and wear of the cutting edge, due to the combination of fabrics and rigid film in their structure.

As far as tool optimization performed for such tools as twist drills, mills, turning tools, or punches is concerned, research can be widely found in the scientific literature; however, there is no research connected with belt perforation tools. Abele and Fujara [5] presented a new holistic method of using computing power for twist drill design and optimization. Li et al. [6] showed a three-dimensional finite element method of milling process for solid carbide end mill design and optimization, where such geometrical parameters as helix angle, rake angle, and number of flutes were optimized based on the target of low cutting forces and temperature. Zong et al. [7] used the FE model to simulate diamond turning process in order to consider the influence of cutting edge radius, rake angle, and clearance on the residual stresses and established an optimal value of rake angle at $15^{\circ}$ and clearance angle at $10^{\circ}$. Jensen et al. [8] presented an optimization of the shape of the draw-die profile with regard to the tool wear using conventional optimization method and explicit FE method, which led to improving the tool life almost twice. Performing the tool optimization based only on the experimental research requires to manufacture a series of tool sets with variable geometries, which is very expensive. This is why computer-aided design (CAD) along with the FEM analyses is widely used for the tool optimization. Based on the analyses, we can choose a few sets of geometrical features, which will be later manufactured and tested to validate the model used and the results obtained. This approach will greatly reduce the costs and will expand the range of tested parameters.

During the tool optimization, various objective functions, designs, and state variables may be used. Venkata Rao and Savsani [9] presented in their work multiple advanced optimization techniques, which was explained on few examples of the optimization of different mechanical designs (gear train, robot gripper, etc.). In general, we can distinguish three main groups of objective functions for tools: exploitation parameters (tool life or wear, process efficiency, tool stiffness, etc.), dynamic parameters (generated forces or stress), and quality parameters (roughness of the surface, deviations, etc.). If we consider the belt punching process, the most important objectives are the lowest perforation force, the longest tool life, and the best quality of the holes. As design variables, the geometrical features like bowl radius, punch-die clearance, punch diameter, or tool angle will be used. Based on the chosen tool geometry, the state variables (equivalent stress, strain, or frictional work) can be obtained and used to determine the objective functions.

Among the searched parameters, the hardest to determine is the tool life. Experimental tests, which will make it possible to specify the tool life, could take a few years and millions of cycles before any usable results are obtained. Because of that, it is necessary to use models for tool life prediction, based on the above-mentioned state variables. In the scientific literature, we can find the correlations between the tool life and the following parameters: cutting edge stress, lateral to normal force ratio, cutting force, temperature, tool wear after low-cycle tests, or some stochastic or genetic algorithms based on previous population of results for specific types of tool. Ko and Kim [10] described an analytical scheme for the prediction of the tool wear by using reformulated Archard's wear model in an incremental form, which is using the normal pressure over the contact area. Oraby and Hayhurst [11] used the ratio of force components acting at the tool tip (radial and feed component of the force) in order to develop the models for tool wear and life estimation. Zhang and Guo [12] proposed a tool wear model, which uses the prediction of the cutting force and the energy consumption in the turning process and validated this model with the experimental results available in scientific literature. Yen et al. [13] stated that in metal cutting, tool wear is strongly influenced by the cutting temperature, contact stresses, and relative sliding velocities at the interface. They claimed that using the FEM simulations to determine the 
above-mentioned variables, it is possible to predict the tool wear evolution and tool life with acceptable accuracy. Hu et al. [14] proposed a novel friction/wear model, which characterizes the evolutions of friction coefficient and the remaining thickness of the coating layer, which can be used to predict the life of coated tools for sheet metal forming process and can be applied to the FE simulation. Salonitis and Kolios [15] presented a methodology for the efficient reliability assessment of cutting tool wear based on the combination of stochastic response surface and surrogate modeling methods combined with Monte Carlo simulations and first-order reliability methods for the estimation of reliability indices taking into an account cutting speed and feed rate. They claimed that the proposed techniques have potential for determining optimal tool life with reduced experimental testing in comparison with pure experimental methods. Kovac et al. [16] also proposed a method, which the main profit is minimizing the number of experiments necessary for acquiring enough input data and they gained it by using genetic algorithms. All above-mentioned tool life estimation models cannot be directly used for an estimation of the punch wear. The important difference between the belt punching process and machining is the magnitude of the tool life. In belt punching, the tool life may exceed 1,000,000 holes, which takes hours and a lot of wasted material, while in machining, the tool life is measured in minutes. Because of that, for the punch optimization, we should use methods based strictly on FEM analyses, which will provide as results to the perforation force to transverse force ratio or the contact pressure on the cutting edge.

The main goal of the presented research is to determine the effective geometry of the piercing punches with a spherical bowl used in the belt perforation process. Any additionally derived characteristics should enable to simply adjust the optimization model to match specific requirements of the manufacturers worldwide. In Section 2, the authors present a brief description of the methodology used in experimental research. In the three following sections, the authors have widely discussed the influence of the punch geometry on the quality of the holes (Section 3), perforation force necessary to perform the process (Section 4), and tool life (Section 5). All these results were combined and used in the punch optimization presented in Section 6 and closed with main conclusions presented in summary (Section 7).

\section{Methodology of research}

In the presented research, the combination of analytical derivations, FEM simulations, and experimental research was used in order to determine the effective geometry of the piercing punch. All presented results were obtained using the test stand designed by authors (Fig. 1), which consists of the punching die with replaceable tools. Its construction was described in details in [2]. The main advantage of the test stand is the zero backlash linear guide, which makes it possible to use a very small clearance between the punch and the die (down to $0.05 \mathrm{~mm}$ ). All the experimental tests were performed on the MTS Insight testing system with load capacity $50 \mathrm{kN}$, where traverse speed $0.5 \mathrm{~mm} / \mathrm{s}$ provided the quasi-static nature of the analyzed process. In order to check a wide spectrum of belt properties, ten different types of belts were tested, in which we can distinguish eight representatives of strong rigid belts with polyamide core (SG500, TTA500N, TTA1000N, M500, TFL7S, TFL10S, TFL15S, XH500-6) and one representative from the two remaining groups of more flexible belts (polyester fabric-reinforced polyurethane belt LAB12E and aramid fiber cord-reinforced polyurethane toothed belt $\mathrm{T} 10 \mathrm{~K})$. For each belt, the rectangular specimens $30 \times 150 \mathrm{~mm}$ were cut, in which five holes were punched with 20-mm spacing, and the force in function of displacement during punching was measured for various sets of tools (punches and dies).

In order to derive the optimization model, only one type of belt (TFL10S) will be used. This type of belt was chosen because it has a combination of the most difficult properties for a perforated belt manufacturers - it is very rigid and has increased strength, which indicates it needs one of the highest perforation forces and the tool wear during its processing should be the worst. Additionally, it has protective gaskets made of the polyamide fabrics which implies that it should be subjected to the tool sharpness and almost all defects common for the belt perforation will occur for this type of belt.

\section{Influence of the geometrical features of the punch on the quality of the hole}

The quality of the punched holes may be evaluated using both quantity and quality criteria. The first parameter used for the quantity analysis of the effect of the punching process is the diameter deviation $\Delta$, which defines the difference between the nominal diameter $D_{\mathrm{N}}$ of the punch and the diameter of the hole. Since the diameters measured in perpendicular dimensions differ due to the orthotropic properties of the polymer composite belts and much more elasticity is visible in the longitudinal direction of the belt than the transverse one, the diameter $D_{\mathrm{L}}$ measured in the longitudinal direction will be taken into account during further analysis. Based on the obtained results, the deviations in the longitudinal directions are 10 times higher than those in the transverse direction, which means that 


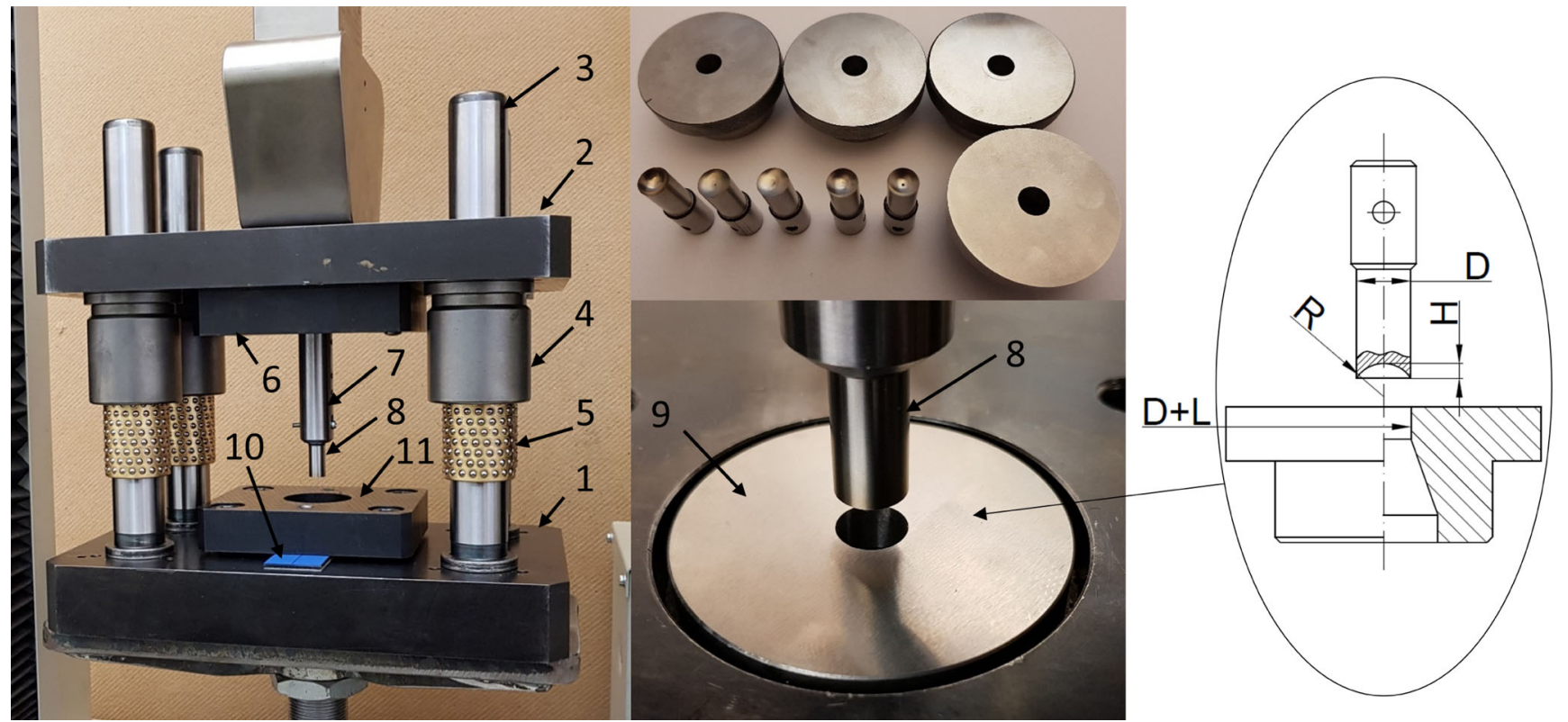

Fig. 1 Punching die and the set of tools used in presented tests with their geometrical parameters: 1-base, 2-head block, 3-guiding column, 4-sleeve, 5-ball bushing, 6-punch plate, 7-punch chuck,
8 - piercing punch, 9-piercing die, 10 - belt specimen, 11-pressure plate, $D$-diameter of the piercing punch, $H$-depth of the spherical bowl, $L$-punch-die clearance, $R$-radius of the piercing punch slight ovality of the holes is present. In order to grade it, the ovality factor $\delta$ was introduced as a ratio of both diameters.

To determine the correlation between the depth of the piercing punch bowl $H$ and the punch-die clearance $L$ with the above-mentioned quantity criteria, the measurement of the hole diameters was taken with a slide caliper with accuracy of $0.01 \mathrm{~mm}$. For each geometry, five holes were measured in both directions and then the average was derived. The obtained results are presented in Table 1 and the characteristics are shown in Fig. $2 \mathrm{a}-\mathrm{c}$. The methodology of the measurement is presented in Fig. 2 d.

Based on the results, there is a negative linear correlation between both analyzed parameters and the depth of the punch bowl $H$. This indicates that the sharper the cutting

Table 1 Measurement results of the hole diameter for TFL10S belt using tool with nominal diameter $D=10 \mathrm{~mm}: P D-$ flat punch and die, $P D S B$ - punch with spherical bowl and die, $R$ - radius of the bowl [mm], $L$ - punch-die clearance [mm]

Diameters of the holes measured in perpendicular directions [mm]

\begin{tabular}{|c|c|c|c|c|c|c|c|c|c|c|c|c|}
\hline Tool set & $D_{\mathrm{L} 1}$ & $D_{\mathrm{T} 1}$ & $D_{\mathrm{L} 2}$ & $D_{\mathrm{T} 2}$ & $D_{\mathrm{L} 3}$ & $D_{\mathrm{T} 3}$ & $D_{\mathrm{L} 4}$ & $D_{\mathrm{T} 4}$ & $D_{\mathrm{L} 5}$ & $D_{\mathrm{T} 5}$ & $D_{\mathrm{L}_{\mathrm{avg}}}$ & $D_{\mathrm{T}_{\text {avg }}}$ \\
\hline PD10-L0.05 & 9.62 & 9.3 & 9.6 & 9.35 & 9.6 & 9.33 & 9.6 & 9.39 & 9.51 & 9.33 & 9.586 & 9.34 \\
\hline PD10-L0.1 & 9.88 & 9.44 & 9.88 & 9.46 & 9.89 & 9.6 & 9.77 & 9.51 & 9.8 & 9.49 & 9.844 & 9.5 \\
\hline PD10-L0.15 & 9.82 & 9.46 & 9.81 & 9.34 & 9.84 & 9.37 & 9.81 & 9.42 & 9.86 & 9.35 & 9.828 & 9.388 \\
\hline PD10-L0.2 & 9.67 & 9.31 & 9.62 & 9.41 & 9.62 & 9.37 & 9.57 & 9.29 & 9.61 & 9.46 & 9.618 & 9.368 \\
\hline PDSB10-R10-L0.1 & 10.33 & 10.01 & 10.33 & 10.01 & 10.23 & 9.98 & 10.17 & 10 & 10.25 & 10.1 & 10.262 & 10.02 \\
\hline PDSB10-R8.5-L0.1 & 10.27 & 10 & 10.25 & 9.95 & 10.19 & 9.99 & 10.2 & 9.98 & 10.2 & 10.03 & 10.222 & 10.03 \\
\hline PDSB10-R7.25-L0.05 & 10.08 & 10.02 & 10.17 & 9.99 & 10.12 & 10.03 & 10.17 & 9.99 & 10.18 & 10.03 & 10.144 & 10.012 \\
\hline PDSB10-R7.25-L0.1 & 10.18 & 10.03 & 10.17 & 10.04 & 10.23 & 10.01 & 10.12 & 10 & 10.23 & 10.03 & 10.186 & 10.022 \\
\hline PDSB10-R7.25-L0.15 & 10.18 & 9.99 & 10.2 & 10.03 & 10.22 & 10.03 & 10.22 & 10.06 & 10.16 & 10.04 & 10.196 & 10.03 \\
\hline PDSB10-R7.25-L0.20 & 10.23 & 10.03 & 10.18 & 10.02 & 10.14 & 10.03 & 10.23 & 10.01 & 10.23 & 10 & 10.202 & 10.018 \\
\hline PDSB10-R6.5-L0.1 & 10.13 & 10 & 10.19 & 10.01 & 10.14 & 10.02 & 10.07 & 10.01 & 10.11 & 9.98 & 10.128 & 10.004 \\
\hline PDSB10-R5.5-L0.05 & 10 & 10.02 & 10.01 & 10.02 & 9.99 & 9.99 & 10 & 10.03 & 10.02 & 10.02 & 10.004 & 10.016 \\
\hline PDSB10-R5.5-L0.1 & 10.02 & 10.01 & 10.05 & 10 & 10.02 & 10 & 10.03 & 10 & 10.03 & 10.02 & 10.03 & 10.006 \\
\hline PDSB10-R5.5-L0.15 & 10.08 & 10.02 & 10.07 & 10.01 & 10.06 & 10.01 & 10.07 & 10.02 & 10.04 & 10.02 & 10.064 & 10.016 \\
\hline PDSB10-R5.5-L0.20 & 10.07 & 10.02 & 10.04 & 10.03 & 10.05 & 10 & 10.05 & 10.02 & 10.07 & 10 & 10.056 & 10.014 \\
\hline
\end{tabular}


edge, the better the quality of the hole we can obtain. Analyzing the influence of the punch-die clearance, we can observe that by increasing the gap between two cutting edges, diameter deviations rise nonlinearly. On the other hand, changing the punch-die clearance has no effect on the ovality of the hole.

As can be observed, the hole diameter for the flat punches is always lower than the nominal value, since the belt is extended during the process and shrinks after the punch goes back to its initial position. On the other hand, for the spherical bowl punches, the holes have slightly greater diameters than the tool. Because some correlations between the hole deviation and the geometry of the tool are present, it could be possible to determine the nominal diameter of the piercing punch, which would compensate the hole deviation. Thanks to that, we would be able to obtain perfect diameter of the holes in the belt, even with less sharp tools. The problem with this approach is the fact that presented correlations are specific for a single type of the belt and may slightly differ for another one. In order to adjust the equipment of the perforating machine for various belts, it will be necessary to use not only different piercing punches but also the dies. It would generate very high cost of exploitation. Using the effective geometry of the tool, which should be properly designed for a universal application, can greatly reduce that cost. Even if the tool life of the sharper piercing punch will be shorter, the wear of the die is much lower than the punch. Applying the constant nominal diameter of the piercing punch will make it possible to use one die for the multiple types of punches.

For the quality analysis, the most important factor taken into account is the presence or absence of the typical defects that occur in the perforated belts. Based on the previous research [2] as the common defects of belt perforation, we can distinguish: conicity or ovality of the holes, fiber pull-out, uneven edge or side surface, and deformation of the covers of the belt. In Fig. 3, selected holes for different geometries of the piercing punch are presented. Comparing the flat punch with all spherical bowl punches, it can be clearly observed that the roughness of the side surface and the shape of the hole contour are greatly improved regardless of the depth of the bowl and clearance. Analyzing the correlation between these parameters and the overall quality of the holes, we can observe that increasing the clearance has a negative effect since the pulled-out fibers occur much more often. Increasing the depth of the bowl should theoretically reduce the fiber pull-out as it makes the punches sharper, but the surface finish and tool condition may affect the quality as well. This means that the theoretically sharper tool may give worse results due to the machining errors (as can be seen for holes made with tools with $H=2 \mathrm{~mm}$ and $H=2.35 \mathrm{~mm}$ ) and it should be considered in the results analysis.
Based on the above-mentioned analysis and the overall experience of the authors obtained by the contact with the industry, the map of hole quality was made (Fig. 4). On this map, the quality of the hole was evaluated in the range of $0-1$, where 1 means $100 \%$ fulfilling the requirements of the belt manufacturers and customers. It should be mentioned that the presented data should be used more for understanding the tendency of how the hole quality varies when using different tool sets rather than for a quantity analysis of the perforation process.

\section{Influence of the geometrical features of the punch and die on the perforation force}

One can find a lot of research that presents an influence of the punch-die clearance on the punching process parameters in metal stamping, such as maximum force, tool wear, and hole quality. Soares et al. [17] reported that the ideal clearance range for thick ductile materials is between 2 and $10 \%$ and that for the values below $5 \%$ the smaller peak of maximum punch force and lower fracture angle is obtained. However, they also mentioned that for very small clearances $(0.2 \%)$, the maximum force increases. On the other hand, they stated that larger punch-die clearance $(15 \%)$ acceptable fracture angle profile is gained, but a large burr height occurs. Subramonian et al. [18] reported that the correlation between the punch-die clearance and the contact stress is the "V" or "U" shaped curve since increasing the clearance changes the shearing-bending ratio in the punching process, which means that there is a range in which the contact stress reaches its minimum. They also stated that this stress level may be used as an indicator of a punch wear and together with the geometry curve can be used to improve the tool life. Lo et al. [19] investigated the effects of punch-die clearance on the burr width of shearing corner and established an analytical model of the dimensional tolerance between punch and punch base, which can be used to predict the burr width and the tool life. However, the above-mentioned correlation for more elastic materials, like polymer composite belts, was not specified.

In Fig. 5, the results for two punches with radius of the bowl 5.5 and $7.25 \mathrm{~mm}$ are presented. Based on the experimental results, a slight difference in the force magnitude is visible, but no explicit nature of the correlation may be determined. The reason for varying perforation force is the tool condition, as was mentioned in Section 3, and since the tests were performed for the two with the best surface finish, the influence of this parameter should be minimized. In order to check the possible dispersion of the results, measurement was made before and after the die sharpening (because the surface milling does not change the geometry of the tool) for eight different types of belts 

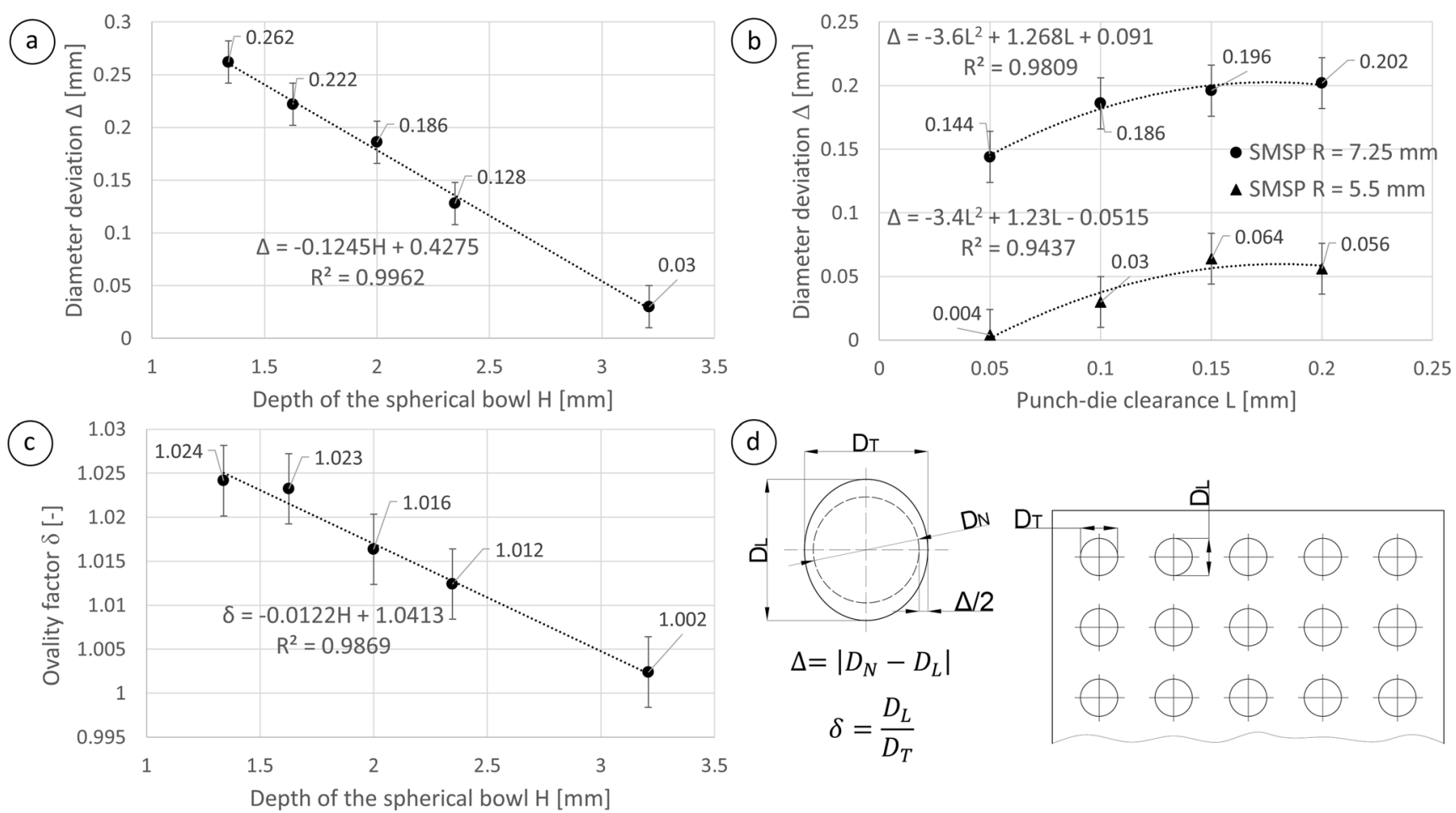

Fig. 2 Correlations between the tool geometry and the quality criteria of the holes for TFL10S belt a-c along with the methodology of their determination $\mathbf{d}$ for $D=10 \mathrm{~mm}$

and the obtained results are presented in Table 2. Based on that, the dispersion of the perforation force was established as the average value of $5 \%$ for the flat punch and $15 \%$ for the spherical bowl punch. Since the differences between extreme values for the experimental tests are $6.5 \%$ and $10.2 \%$, we can conclude that for the elastic materials, the

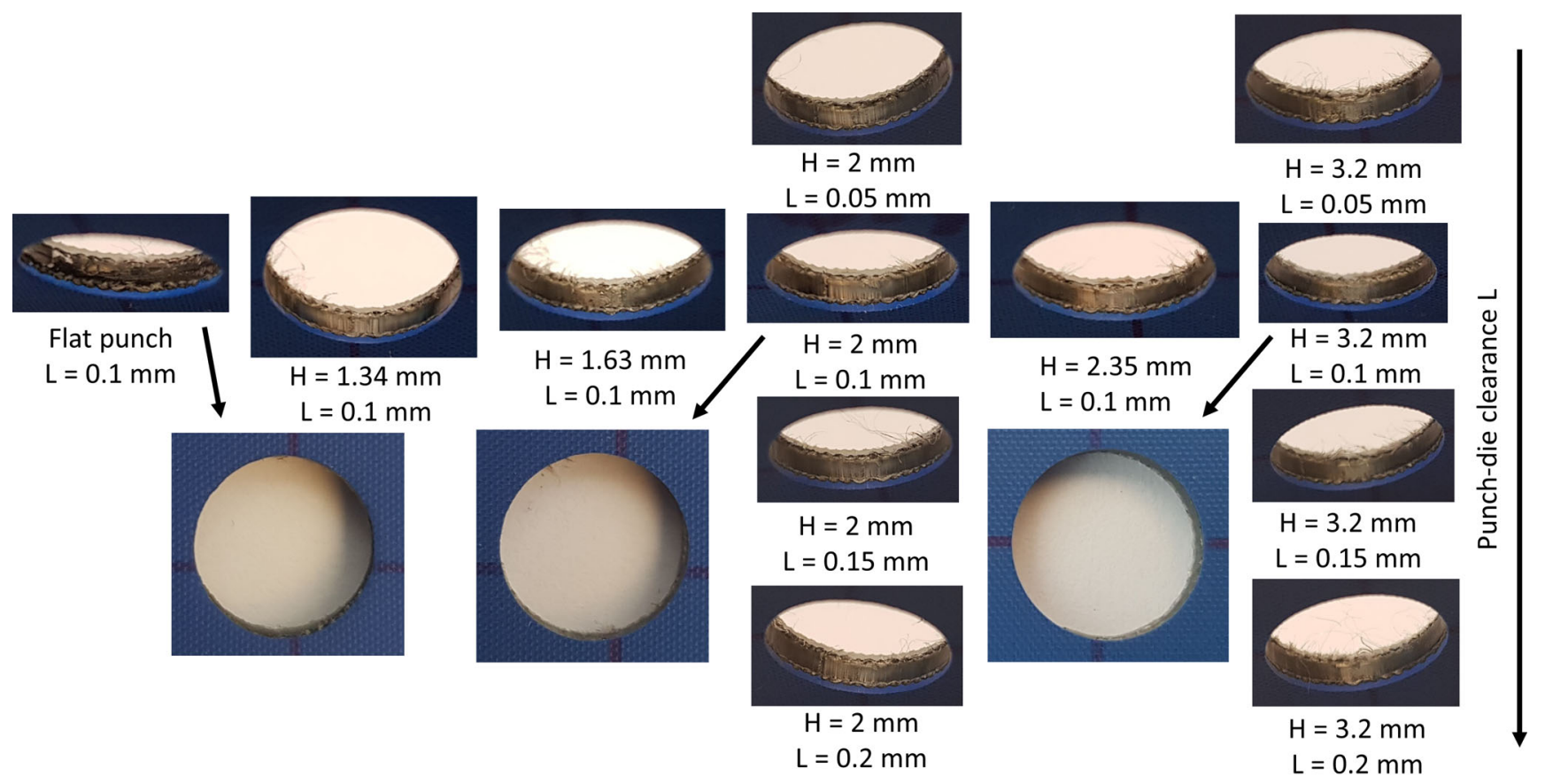

Depth of the punch bowl $\mathrm{H}$

Fig.3 Quality of the holes for different geometries of the piercing punch and belt TFL10S and diameter $D=10 \mathrm{~mm}$ 
Fig. 4 Map of the quality of the holes for different geometries of the piercing punch and belt TFL10S and diameter $D=10$ $\mathrm{mm}$

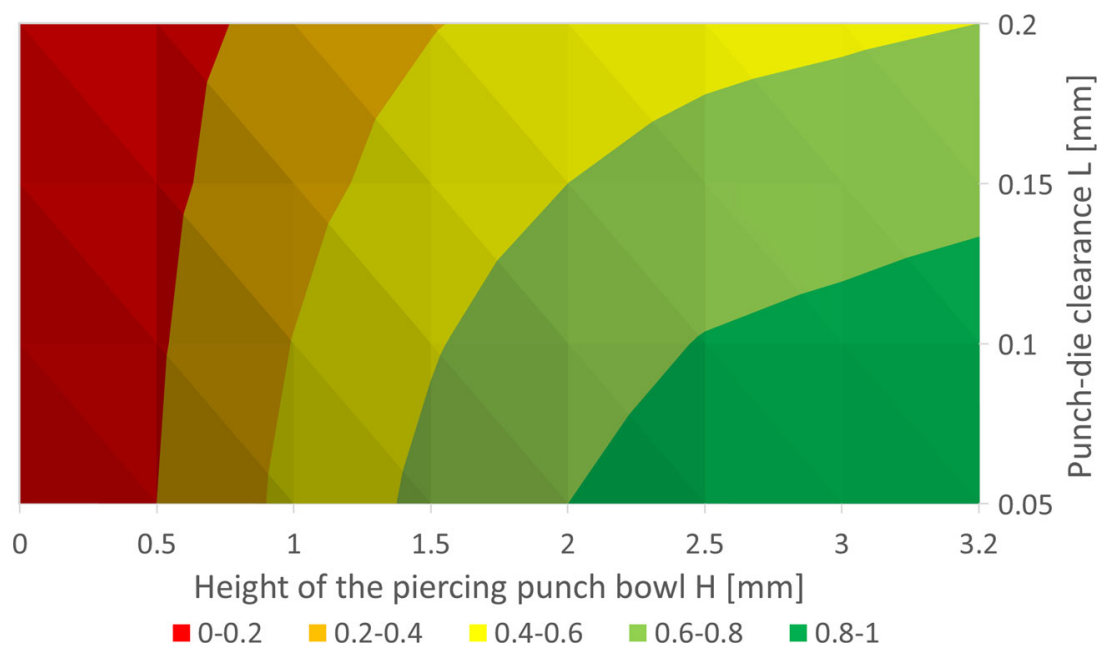

The obtained results for flat and spherical bowl punches are presented in Table 3. Since the clearance influence was neglected, only three geometrical parameters of the spherical bowl punch are considered in the analyses: punch diameter $D$, bowl radius $R$, and depth of the bowl $H$ (Fig. 1). Because determining two of the parameters fully defines the geometry of the punch and due to the technological aspect of choosing the proper tool for the grinding process of the punches, the radius of the bowl will be specified and the depth will be calculated. The diameter of the punch has to be specified because it strictly corresponds with the hole size and cannot be treated as a result value.

Taking into consideration the effect of the tool condition on the perforation force value, it is almost impossible to determine the force characteristics strictly on the experimental results. It would require a set of precisely manufactured tools with various geometrical features, which covers a whole range of possible bowl depth (maximum depth of the punch has to be lower than $0.5 D$ ).
Fig. 5 Correlation between the punch-die clearance and the perforation force obtained from both FEM and experimental tests for TFL10S belt and diameter $D=10 \mathrm{~mm}$

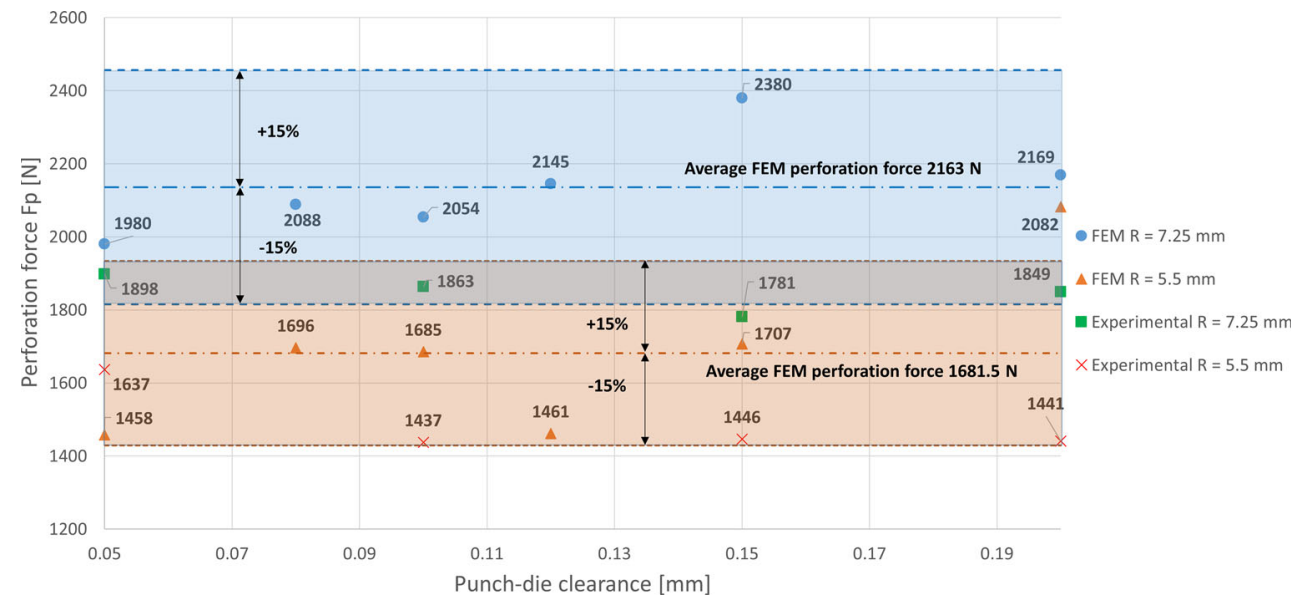


Table 2 Comparison of the experimental tests results before and after the die sharpening for various types of belts, diameter $D=10 \mathrm{~mm}$ and bowl radius $R=7.25 \mathrm{~mm}$

\begin{tabular}{|c|c|c|c|c|c|c|c|c|}
\hline Punch type & M500 & SG500 & TFL7S & TFL10S & TFL15S & TTA500N & TTA1000N & XH500-6 \\
\hline \multicolumn{9}{|c|}{ Perforation force before the die was sharpened $[N]$} \\
\hline Flat & 3558 & 2713 & 4143 & 5086 & 6168 & 3191 & 4401 & 3471 \\
\hline Spherical bowl & 1413 & 1136 & 1682 & 2138 & 2810 & 1181 & 1780 & 3677 \\
\hline \multicolumn{9}{|c|}{ Perforation force after the die was sharpened $[N]$} \\
\hline Flat & 3497 & 2759 & 3987 & 4633 & 5821 & 3177 & 4392 & 3592 \\
\hline Spherical bowl & 1240 & 939 & 1498 & 1863 & 2502 & 1013 & 1598 & 3024 \\
\hline \multicolumn{9}{|c|}{ Percentage difference of the force value [\%] } \\
\hline Flat & 1.16 & 1.7 & 3.77 & 8.91 & 5.63 & 0.44 & 0.2 & 3.49 \\
\hline Spherical bowl & 13.95 & 20.98 & 12.28 & 14.76 & 12.31 & 16.58 & 11.39 & 21.59 \\
\hline
\end{tabular}

Although the punches with spherical bowl make it possible to achieve better performance of the perforation process, their manufacturing is much more complicated compared with the simple flat punches. The main technical issues are the grinding process of the punch bowl (sharpening) and maintaining proper tolerances on the geometrical parameters of the punch. One of the reason for abovementioned issues is the necessity of using HSS steel with hardness $64 \mathrm{HRC}$. Because of this, the machining has to be performed after a heat treatment (hardening), which indicates that special tools have to be used. Additionally, the complex shape of the punch requires specific kinematics of the tool drive. All these issues may be solved by proposing the construction of the machine for piercing punch spherical bowl precision grinding, which may be considered by authors as a future design and research objective. But for now, the cost of machining a set of these tools is too high to perform the whole research based on the experimental tests.

For that reason, the authors have built the FEM model in ABAQUS/Explicit, which makes it possible to analyze different combinations of the geometrical parameters and obtain necessary characteristics for the tool optimization process. The construction of the FEM model is presented in Fig. 6. The assembly consists of four instances: TFL10S belt, the piercing punch, die, and blank holder. Beside the belt, all the instances were modelled as steel elements and

Table 3 Comparison of the experimental tests and FEM analyses results for belt TFL10S

\begin{tabular}{|c|c|c|c|c|c|c|c|}
\hline Punch type & $D[\mathrm{~mm}]$ & $R[\mathrm{~mm}]$ & $L[\mathrm{~mm}]$ & $H[\mathrm{~mm}]$ & $F_{\mathrm{P}_{\exp }}[\mathrm{N}]$ & $F_{\mathrm{P}_{\mathrm{FEM}}}[\mathrm{N}]$ & $\delta_{\mathrm{FP}}[\%]$ \\
\hline \multirow[t]{4}{*}{ Flat } & 10 & - & 0.1 & - & 4633 & 4723 & 1.9 \\
\hline & 8 & & & & 3485 & 4244 & 21.8 \\
\hline & 6 & & & & 2643 & 3511 & 32.8 \\
\hline & 5 & & & & 2155 & 2926 & 35.8 \\
\hline \multirow[t]{14}{*}{ Spherical bowl } & 10 & 7.25 & 0.05 & 2 & 1898 & 1980 & 4.3 \\
\hline & 10 & 7.25 & 0.15 & 2 & 1781 & 2380 & 33.6 \\
\hline & 10 & 7.25 & 0.2 & 2 & 1849 & 2169 & 17.3 \\
\hline & 10 & 5.5 & 0.05 & 3.2 & 1637 & 1458 & 10.9 \\
\hline & 10 & 5.5 & 0.15 & 3.2 & 1446 & 1707 & 18 \\
\hline & 10 & 5.5 & 0.2 & 3.2 & 1461 & 2082 & 44.5 \\
\hline & 10 & 10 & 0.1 & 1.34 & 2458 & 2412 & 1.9 \\
\hline & 10 & 8.5 & 0.1 & 1.63 & 2680 & 2376 & 11.3 \\
\hline & 10 & 7.25 & 0.1 & 2 & 1863 & 2054 & 10.3 \\
\hline & 10 & 6.5 & 0.1 & 2.35 & 2122 & 1935 & 8.8 \\
\hline & 10 & 5.5 & 0.1 & 3.2 & 1437 & 1685 & 17.3 \\
\hline & 8 & 7.25 & 0.1 & 1.2 & 2109 & 1986 & 5.8 \\
\hline & 6 & 7.25 & 0.1 & 0.65 & 2429 & 2073 & 14.7 \\
\hline & 6 & 7.25 & 0.1 & 0.45 & 2140 & 1837 & 14.2 \\
\hline
\end{tabular}


Fig. 6 Construction of the FEM model

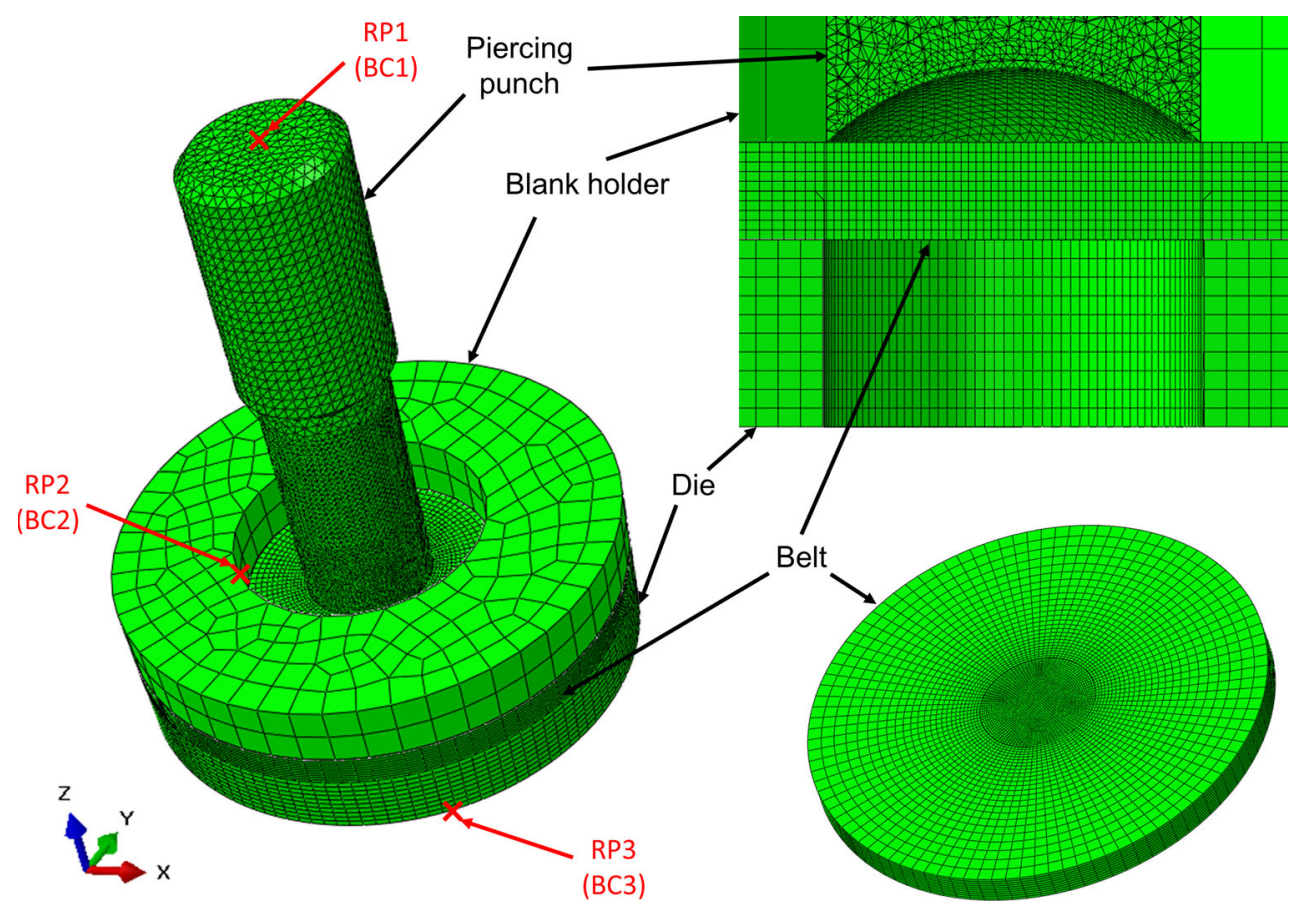

treated as rigid bodies using a proper constrain between an instance and selected reference points RP1, RP2, or RP3. The kinematic extortion of the piercing punch was created by applying the boundary condition BC1 to RP1 point. This BC sets V3 value as $-0.0005 \mathrm{~m} / \mathrm{s}$ and resets other angular or linear velocities as 0 , leaving only one active degree of freedom. The remaining points RP2 and RP3 were fixed with ENCASTRE boundary condition, which blocked all the degrees of freedom. The belt was modelled as a deformable part and its properties were defined according to Table 4. Plastic properties of the material were assumed as isotropic and were obtained as tabular values from the experimental stress-strain curve, where plastic strain 0 occurs at $112 \mathrm{MPa}$. The damage of the material was modelled with the simplified Johnson-Cook model [3], where the deformation rate and temperature are insignificant ( $d_{4}$ and $d_{5}$ equal 0 ). The remaining J-C parameters are shown in Table 4. Damage evolution was specified by the displacement at failure parameter and varies depending on the geometry of the piercing punch. The interaction in the model was made as a general contact and its properties were defined with tangential behavior friction coefficient 0.6 and normal behavior of "hard" contact. The die, belt, and blank holder were meshed with hexahedral, 3D stress, linear C3D8R explicit elements. The belt was divided for partition that both cutting edges have a contact with the same element. The cutting edges along were divided into 100 elements on its circumference. Due to the complex geometry, the grip part of the punch was meshed with tetrahedral C3D10M elements. Mesh control used in the model was set to obtain 10 elements on the thickness belt of size $0.00026 \mathrm{~m}$ each and the diameter of the hole was divided into 50 elements. Although it may be considered as a coarse mesh, the authors realized that increasing the number of elements on the thickness of the belt does not change the obtained results more than a few percent, but greatly increases the computational time and the problems with element distortion occur more often. In order to model the fracture of the belt instance, element deletion was enabled. The results of the reaction force RF3 were taken from the history output for RP1 point. The time period of the analysis was $10 \mathrm{~s}$. In order to reduce the computational time, a mass scaling was used with target time increment 0.001 . It was possible due to the low velocity and quasi-static character of the test.

The validation of the presented FEM model was made based on the comparison of the experimental and simulational results. The example comparison for a TFL10S belt and punch with diameter $10 \mathrm{~mm}$ and radius $7.25 \mathrm{~mm}$ is presented in Fig. 7. All the experimental results used for a model validation are presented in Table 3 along with its simulational equivalent and the obtained error. Based on the results obtained for a spherical bowl punches, the

Table 4 Parameters used in the FEM analysis

$\left.\begin{array}{llllll}\hline \rho & E & v & d_{1} & d_{2} & d_{3} \\ {\left[\mathrm{~kg} / \mathrm{m}^{3}\right]} & {[\mathrm{MPa}]} & {[-]} & {[-]} & {[-]}\end{array}\right)$




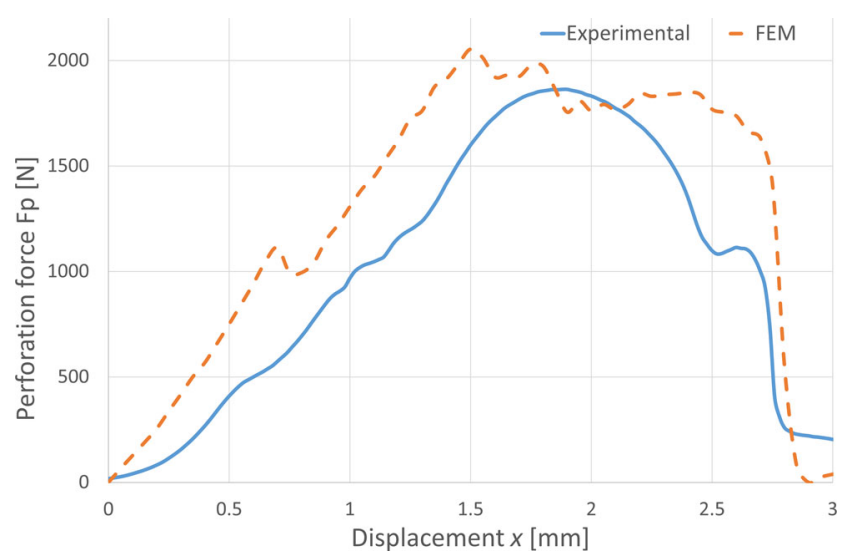

Fig. 7 Example of the comparison of the experimental and FEM analysis results for TFL10S belt, punch diameter $D=10 \mathrm{~mm}$, bowl radius $R=7.25 \mathrm{~mm}$, and punch-die clearance $L=0.1 \mathrm{~mm}$

FEM model inaccuracy was established at the average level of $15 \%$. If we analyze the results for a flat punch, we can conclude that the convergence of the model decreases, especially for smaller diameters. It means that the presented model is adequate for spherical bowl punches, but not for the flat ones.

Based on the proposed model, the simulations for the punches with a spherical bowl and diameters of 5, 6, 8, and $10 \mathrm{~mm}$ were performed. For each diameter, at least six different bowl radii were analyzed. The example of the obtained stress distribution for a TFL10S belt and punch with diameter $10 \mathrm{~mm}$ and radius $7.25 \mathrm{~mm}$ is presented in Fig. 8. Since changing the geometry of the punch had an effect on the element size in the mesh, it was necessary to adjust each model in order to obtain proper results. The modified parameter was the displacement at failure, which was used for steering the element deletion process. The adjustment was made until the moment of failure corresponded with reaching the punch displacement similar to the thickness of the belt (Fig. 8). Since the wide range of the geometrical parameters occurs in the presented research, the displacement at failure varies from 0 to 0.01 , with an average order of magnitude $10^{-5}$. The example results of

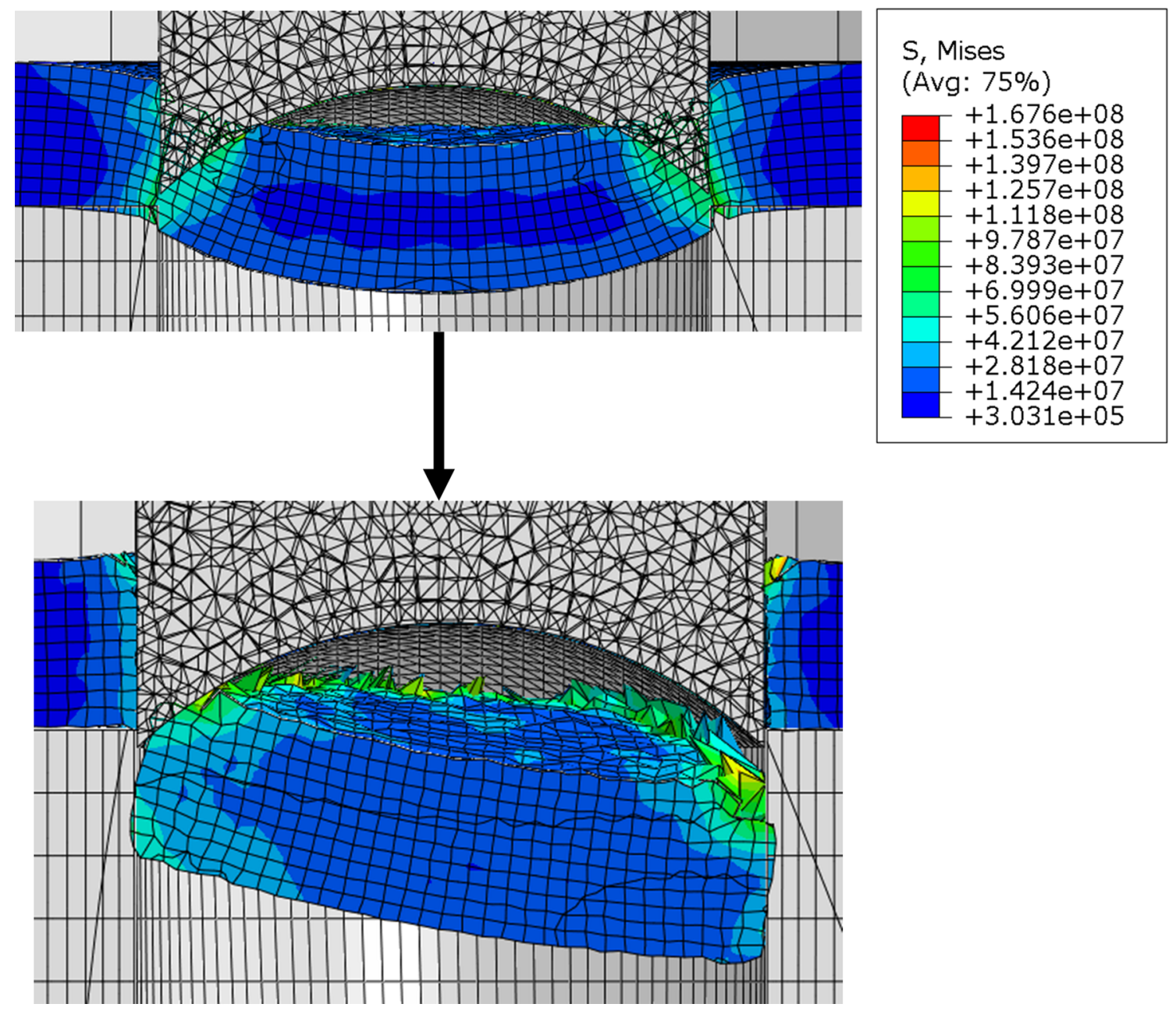

Fig. 8 Example of the simulational results FEM analysis results for TFL10S belt, punch diameter $D=10 \mathrm{~mm}$, bowl radius $R=7.25 \mathrm{~mm}$, and punch-die clearance $L=0.1 \mathrm{~mm}$ 

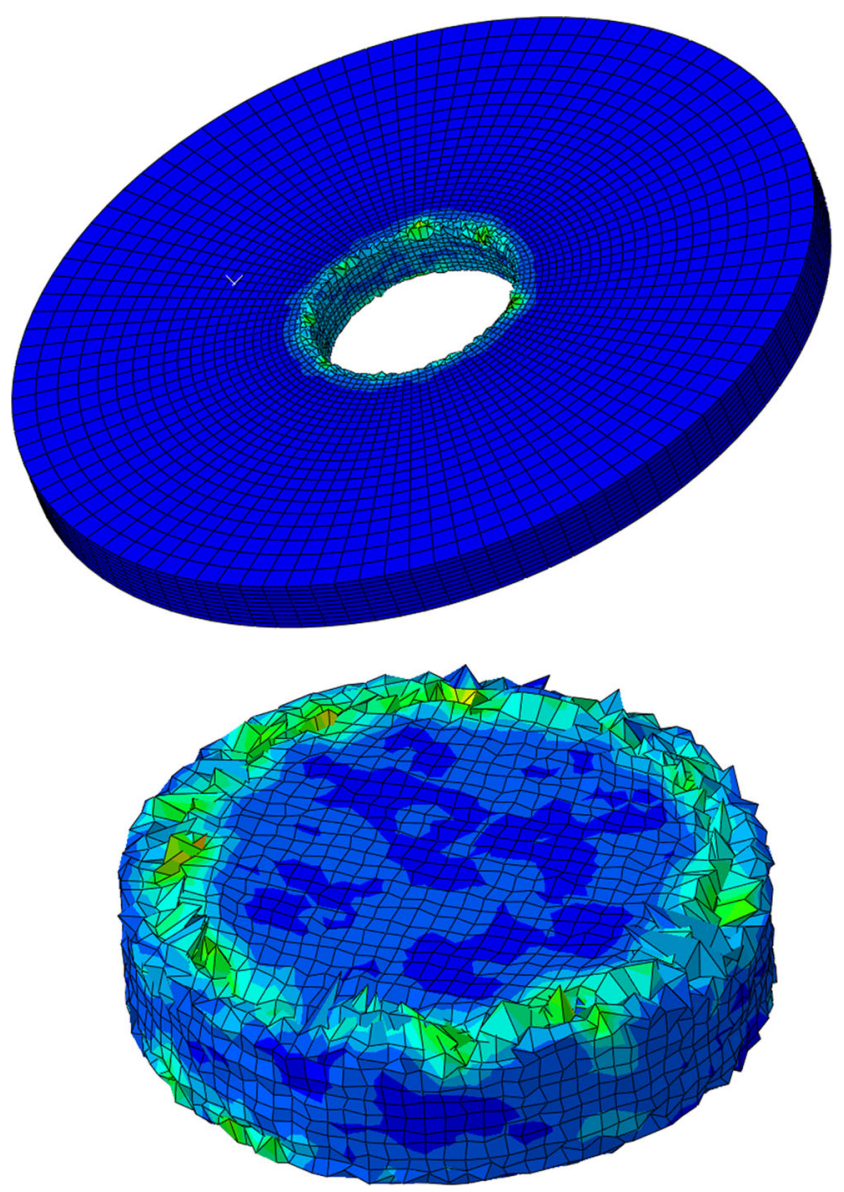

Fig. 9 Example of the comparison of the experimental and FEM analysis results for TFL10S belt, punch diameter $D=10 \mathrm{~mm}$, bowl radius $R=7.25 \mathrm{~mm}$, and punch-die clearance $L=0.1 \mathrm{~mm}$

the analysis in a form of perforated belt TFL10S and the scrap are presented in Fig. 9.

The standard result of the FEM analysis is the determined state of stress and strain in the considered material [20]. Depending on the specificity of the analyzed process, the stress state may be key information and for another ones, the strain state may be more important. The example may be the detailed analysis of the strain distribution in the process of deep drawing [21, 22]. For the authors, the key information obtained from the FEM analyses is the peak perforation force. The divergence between the force characteristics obtained from simulations and experiments is caused by the simplification of using an isotropic approach to belt material modelling, which is in reality the composite with orthotropic mechanical properties. Additionally, the multilayer composite is modelled as a homogenous material and the damage model does not take into account the fracture between the layers. Nevertheless, if we consider that the peak value of the perforation force is crucial information in the punch optimization, we can consider the presented model as useful enough. This approach was previously presented in $[2,3]$ and the obtained results have proved that considering the composite as an equivalent homogenous material in FEM analyses may be used in this application and it was supported with multiple examples found in scientific literature [23-31]. However, using only FEM analyses may give some false results connected with the mesh or poorly chosen failure parameters, which is why authors used a combination of both methods of research in which the experimental tests results are used for model verification.

In Fig. 10, the obtained results for the punch with diameter $10 \mathrm{~mm}$ are presented along with determined forcebowl depth characteristic. On the chart, the upper limit of the perforation force (which corresponds with the values obtained for a flat punch) was marked for $H=0$ as well as other experimental results. As can be observed, using the exponential estimation gives proper results only in the limited range of bowl depth (lower than $2 \mathrm{~mm}$ ) and the error increases for sharper tools. Although the characteristic is going to infinity but for a very small bowl depth, it corresponds with the marked limit, which proves the correctness of the approximation in that range. On the other hand, using the exponential estimation in the limited range, in which the effective depth of the bowl should lie $(1.33<H<3.65$ for $D=10 \mathrm{~mm})$, will not provide proper results for very flat tools. That is why the authors decided to use the complex estimation function, which is the combination of both exponential estimations and may be defined as follows:

$$
F_{\mathrm{P}}= \begin{cases}-551.1 \ln (H)+2461.2 & \text { if } H \leq 1.25 \mathrm{~mm} \\ -961.7 \ln (H)+2790.4 & \text { if } H>1.25 \mathrm{~mm}\end{cases}
$$

As can be observed, the trends derived from the experimental and FEM results may slightly differ. The curve fitting is much better for the FEM results, since the influence of the tool machining precision is here neglected. However, it can be seen that all the results lie within the area established from the experimental points, which proves the appropriate quality of the model. It also shows that depending strictly on the experimental research may lead to more inadequate results than using the combination of both experimental and simulational methods.

The same analyses were performed for the punch with diameters 5, 6, and $8 \mathrm{~mm}$ and the results for all the FEM simulations are presented in Fig. 11a. The obtained characteristics may be useful for the optimization of the punches with the exact same diameter, but for a different one, it is necessary to find the correlation between both geometrical features of the tools. As can be analyzed from the Fig. 11a, punches with the same bowl depth $H$, but smaller diameter $D$ provide more force reduction, because they are much sharper than their equivalent with a higher diameter. Additionally, a positive linear correlation between 
the diameter $D$ and perforation force for the flat punch is visible (Table 3), because increasing the diameter extends the cutting edge, which leads to increasing the shearing area and as a result decreasing the shearing stress for the same force value. Based on that, the correlation of the bowl depth to the punch area indicator $\left(H / D^{2}\right)$ was found and presented in Fig. 11b. Thanks to that equation, it is possible to estimate the perforation force value not only for a discrete sets of geometrical features of the piercing punch, but also for a continuous range of parameters, which is crucial in the tool optimization process.

\section{Influence of the geometrical features of the punch and die on the tool life}

The last and the hardest part of the punch optimization is to estimate the tool life and to find its correlation with its geometry. As was stated in Section 1, the most adequate method is using analysis of the forces. In the literature, one can find multiple examples which present the correlation between the tool wear and the cutting forces [32-36]. For that reason, the load distribution for a spherical bowl punch was analyzed and the obtained model is presented in Fig. 12. Since the life of the tool depends on the frictional wear, which can be evaluated by measuring the radius of the cutting edge $r$, it was assumed that higher friction force will cause faster wear and will shorten the tool life. This assumption was made based on [37], who reported that increased flank wear results in the increased area of contact and increased coefficient of friction and presented the flank wear modelling method based on the friction.

In order to analyze the forces in the perforation process, the axial cross-section of the punch has to be considered. The force $F_{P}$ is the force necessary to perform the cutting and is applied axially to the punch. Its value depends on the sum of all resistances which occur in the process. If we analyze the whole $360^{\circ}$ model of the punch, the transverse forces $F_{\mathrm{T}}$ will equilibrate each other. To analyze the ratio of both of these forces, the infinitesimal radial slice should be considered. Since the cross-section is symmetrical, the force which will be generating the vertical pressure of the piercing punch on the perforated belt $p_{\mathrm{V}}$ on each side of the axis equals $0.5 F_{\mathrm{P}}$. Because the bowl is spherical, the result force of both these forces can be considered as radial force $F_{\mathrm{R}}$. Based on that assumption, the following correlation between above-mentioned forces can be derived.

$$
F_{\mathrm{R}}=\sqrt{F_{\mathrm{T}}^{2}+\left(\frac{1}{2} F_{\mathrm{P}}\right)^{2}}
$$

If we introduce the $\alpha$ angle as shown in the Fig. 12, the radial force can be also derived with the following equation:

$F_{\mathrm{R}}=\frac{1}{2} F_{\mathrm{P}} \cos \alpha$.

Based on Eqs. 2 and 3, the $\alpha$ angle can be derived as the function of the ratio of perforation force $F_{\mathrm{P}}$ and transverse force $F_{\mathrm{T}}$.

$\alpha=\arctan \left(2\left(\frac{F_{\mathrm{P}}}{F_{\mathrm{T}}}\right)^{-1}\right)$

In the presented model, the authors have found the positive correlation between the tool life and the ratio of perforation force $F_{\mathrm{P}}$ (which can be obtained from FEM analyses) and transverse force $F_{\mathrm{T}}$ (which can be calculated analytically). The friction force $F_{\mathrm{F}}$, which is responsible for a tool wear, can be derived in a single discretized point that is the tangential force to the spherical bowl of the punch. Because of that, the radial force $F_{\mathrm{R}}$ is treated as its normal force. Using the Coulomb friction law, the force can be derived as shown in Eq. 5:

$F_{\mathrm{F}}=F_{\mathrm{R}} \cdot \mu$,

where $\mu$ is the friction coefficient.

Because the friction and radial forces are perpendicular to each other, the angle between the transverse force $F_{\mathrm{T}}$ and the friction one equals $\alpha$. This indicates that the vertical component of the friction force $F_{\mathrm{FV}}$ can be derived based on the following equation:

$F_{\mathrm{FV}}=F_{\mathrm{F}} \sin \alpha$.

Based on the above-mentioned correlations, three resistant forces can be distinguished: resistance of the axially compressed material $F_{\mathrm{M}}$, vertical component of the friction force $F_{\mathrm{FV}}$, and friction on the inside surface of the spherical bowl $F_{\mathrm{FO}}$. It can be induced that following force sum will be present:

$\frac{1}{2} F_{\mathrm{P}}=F_{\mathrm{M}}+F_{\mathrm{FO}}+F_{\mathrm{F}} \sin \alpha$

Because of the high stiffness of the punch and axially symmetrical load, the friction on the outer surface $F_{\mathrm{FO}}$ of the model is negligible and in the real conditions, this resistance will be a result of uneven surface of the crosssection separated from the scrap.

$F_{\mathrm{FO}} \ll F_{\mathrm{FV}}$

This means that if we subtract the vertical projection of the friction force inside the bowl $F_{\mathrm{FV}}$, we will obtain the value of the material resistance $F_{\mathrm{M}}$ in the punching process. However, the value will not be constant, because the pressure area changes in a nonlinear way during further penetration. It was observed that the peak value of the 


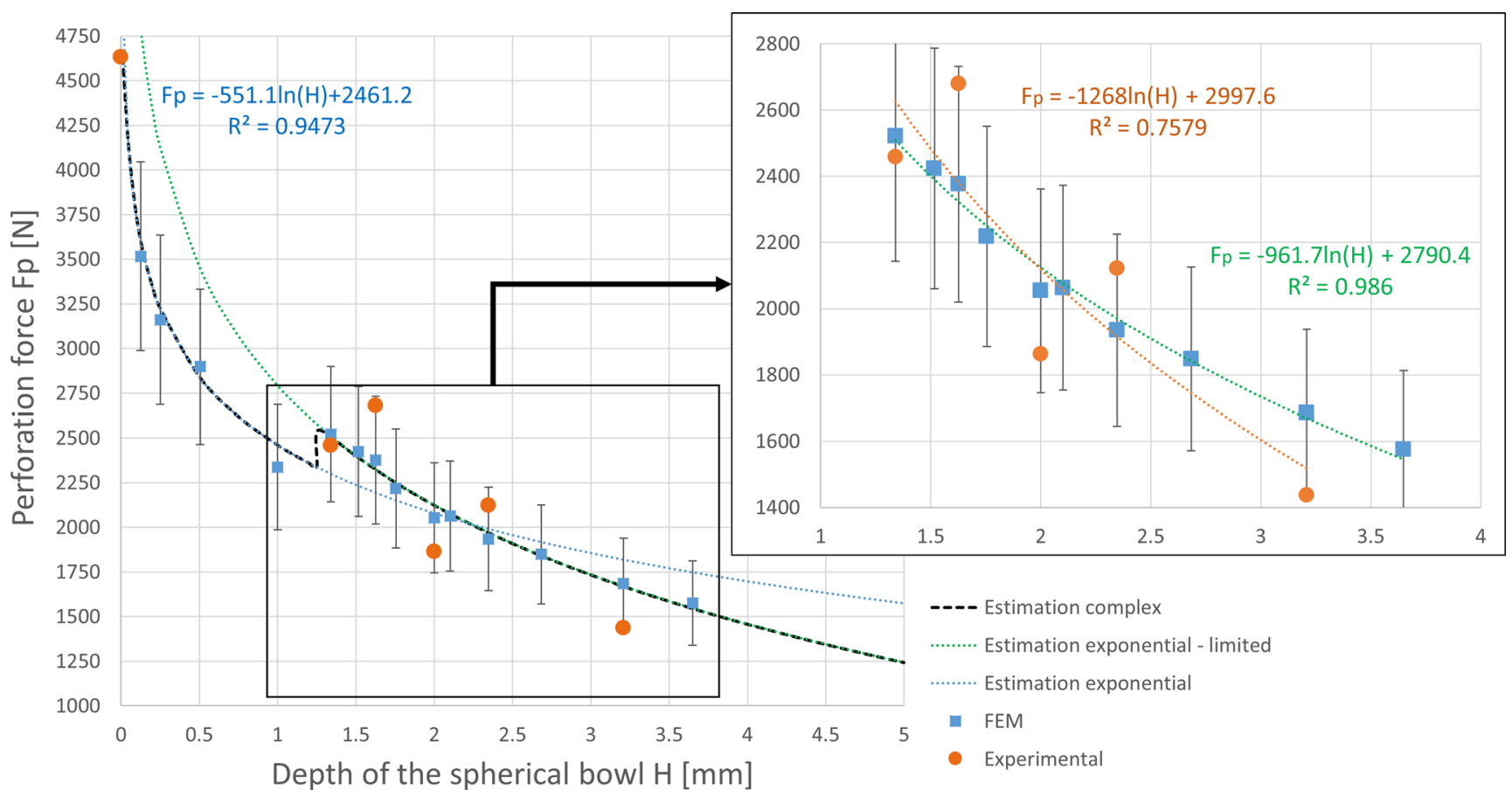

Fig. 10 Correlation between the depth of the spherical bowl and the perforation force obtained from FEM analyses and experimental research for the punch with diameter $D=10 \mathrm{~mm}$ and TFL10S belt

material resistance was lower for the punches with the same diameter and deeper spherical bowl (especially the one whose depth was higher than the material thickness), as well as for the punches with similar sharpness of the punch but a lower outer diameter. This may be one of the important reasons why sharpening the cutting edge leads to force reduction.

$F_{\mathrm{M}}=\frac{1}{2} F_{\mathrm{P}}-F_{\mathrm{F}} \sin \alpha$
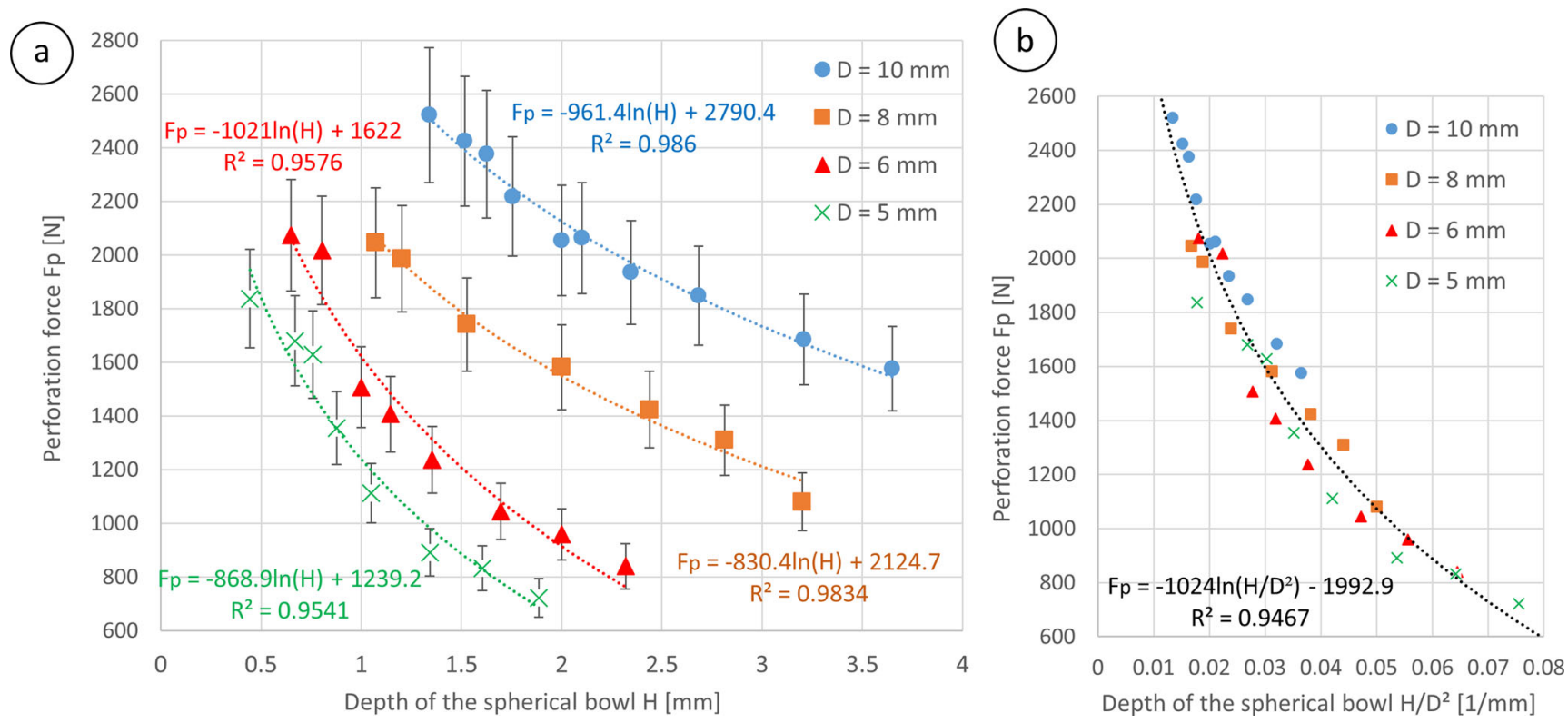

Fig. 11 Comparison between the depth of the spherical bowl and the perforation force correlation by FEM analyses for belt TFL10S and different diameters of the punch (a) and the function of the perforation force estimation (b) 


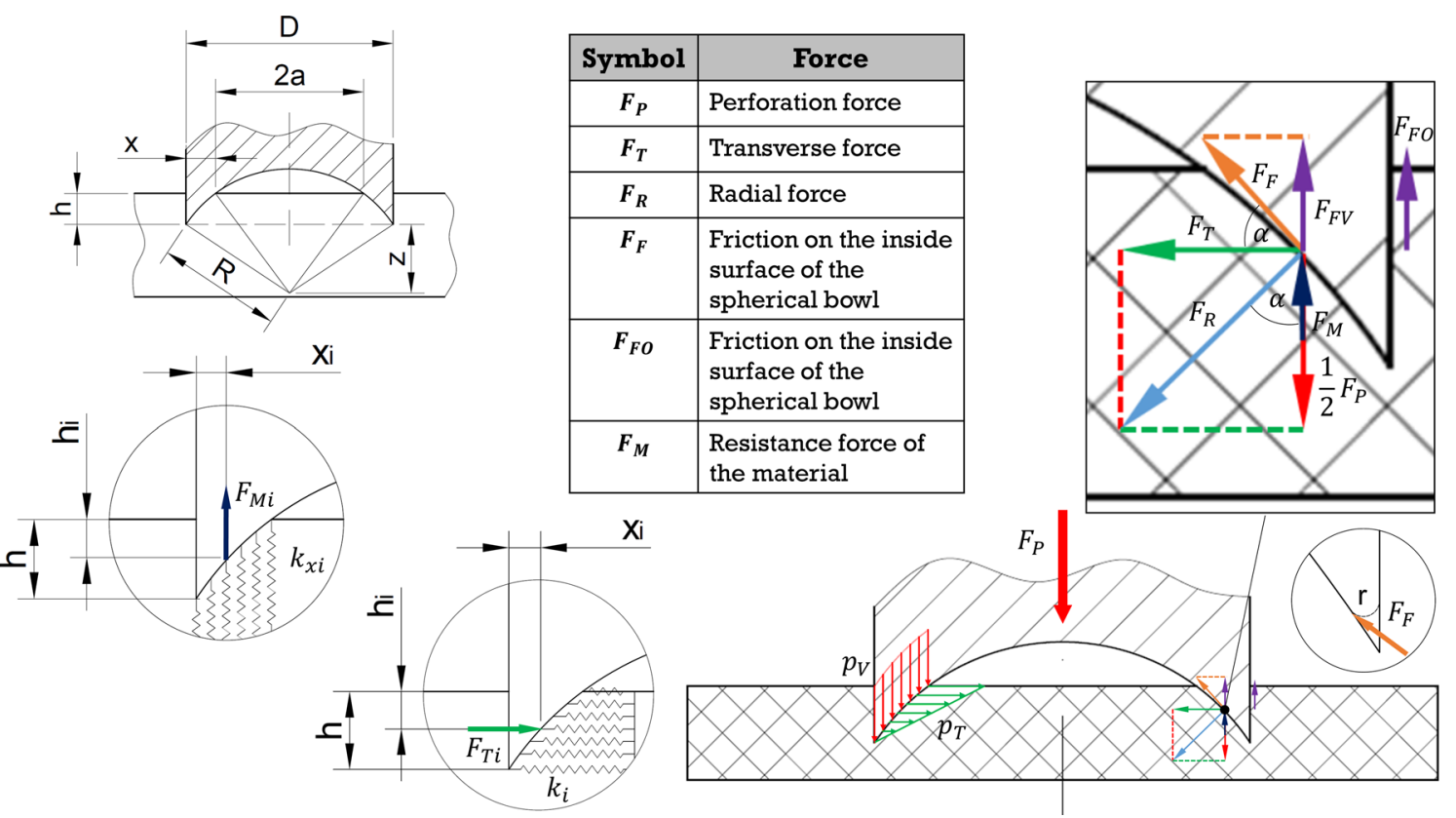

Fig. 12 Load distribution for the spherical bowl punch during perforation: $p_{\mathrm{V}}$-vertical pressure of the piercing punch on the perforated belt, $p_{\mathrm{T}}$-transverse pressure of the piercing punch on the perforated belt, $F_{\mathrm{Ti}}, F_{\mathrm{Mi}}$-force of the spring used for material modelling in the point i, $k_{i}, k_{x i}$-constant of the spring used for material modelling in the point $i, x$-distance between the outer surface of the punch and the contact point of the inner surface of the spherical bowl with perforated belt, $h$-depth of the penetration, $D$-diameter of the punch, $R$-radius of the spherical bowl, $r$-radius of the cutting edge

$F_{\mathrm{Ti}}=k_{i} \cdot x_{i}$

$k_{i}=\frac{E A}{l_{0}}=\frac{E \cdot D \cdot h}{\frac{1}{2} D}=2 E \cdot h$,

where $n$-number of discretized points on the penetration length [-] $E$-Young's modulus [MPa], $A$ - area of transverse compression $\left[\mathrm{mm}^{2}\right], l_{0}$-length of the undeformed

$F_{\mathrm{T}}=\frac{\sum_{i=1}^{n} F_{\mathrm{Ti}}}{n}$,
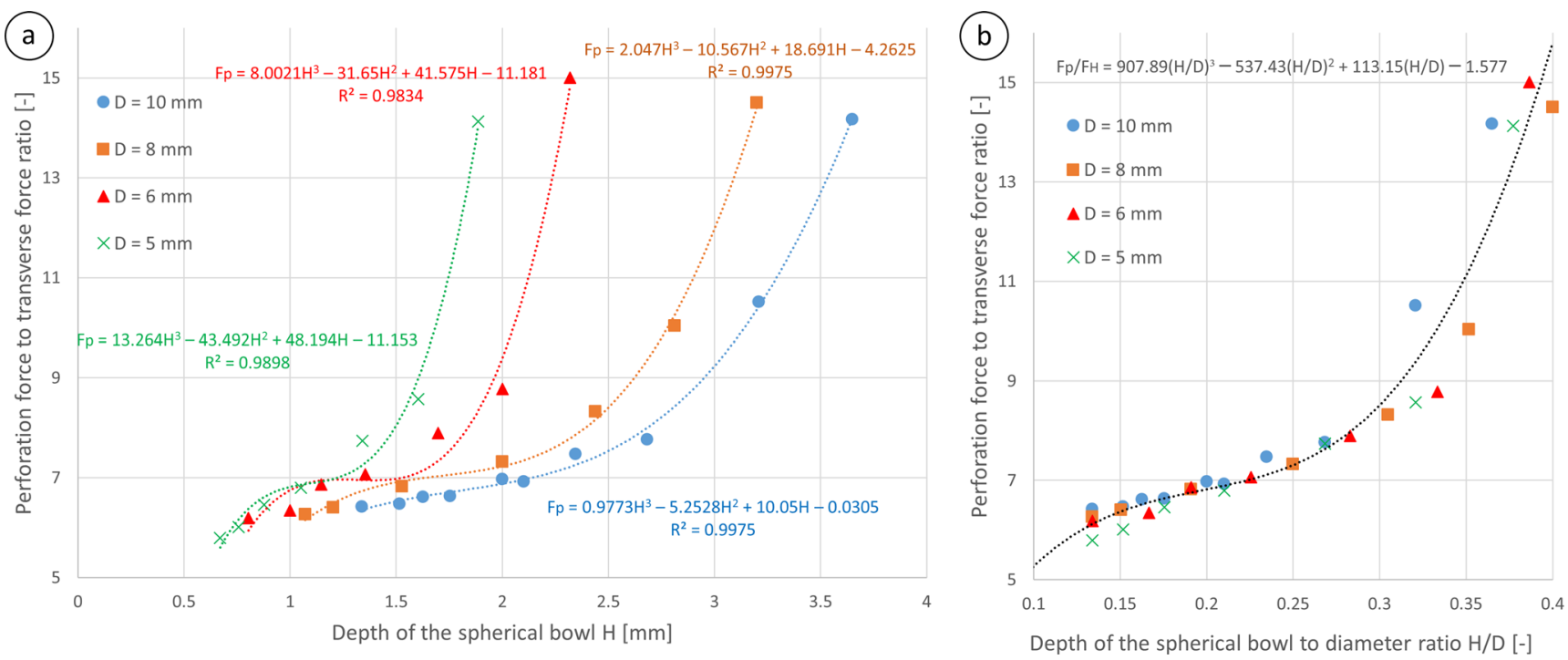

Fig. 13 Comparison between the depth of the spherical bowl and the tool life correlation for TFL10S belt and different diameters of the punch (a) and the function of the tool life estimation (b) 
material $[\mathrm{mm}]$. Since deeper penetration increases the number of parallel springs in the material model, the spring constant increases as a linear function of the depth of penetration. The displacement of each elemental spring changes according to the function $x(h)$.

$x(h)=\frac{1}{2} D-\sqrt{\frac{1}{4} D^{2}-2 h \sqrt{R^{2}-\frac{1}{4} D^{2}-h^{2}}}$

The same methodology can be used to derive the resistance of the compressed material $F_{\mathrm{M}}$, as shown in Fig. 12 and Eqs. 14-16:

$F_{\mathrm{M}}=\frac{\sum_{i=1}^{n} F_{\mathrm{Mi}}}{n}$,

$F_{\mathrm{Mi}}=k_{x i} \cdot h_{i}$,

$k_{x i}=\frac{E A}{l_{x 0}}=\frac{E \cdot \pi D \cdot x}{t}$

where $l_{x 0}$-length of the undeformed material $[\mathrm{mm}], t-$ thickness of the belt [mm].

Taking into consideration the performed force analysis, if the perforation force to transverse force ratio $F_{\mathrm{P}} / F_{\mathrm{T}}$ rises, the $\alpha$ angle decreases, as can be seen in Eq. 4. This leads to increasing the radial force $F_{\mathrm{R}}$ according to the Eq. 3. The following changes result in increasing the frictional force $F_{\mathrm{F}}$. As was stated previously, this force is responsible for the tool cutting edge wear, which implicates that based on the value of the perforation force to transverse force ratio, we can estimate the tool life of the piercing punch.

Based on the presented methodology, the characteristics of the perforation to transverse force ratio were determined for punches with diameters $5,6,8$, and $10 \mathrm{~mm}$ and are presented in Fig. 13a. In order to perform the optimization in a continuous range and considering that the sharpness of the punch (which depends on the bowl depth to punch diameter ratio $H / D$, as was stated in Section 4) has an influence on the tool life, universal correlation was derived and presented in Fig. 13b. It is worth mentioning that the obtained value of the force ratio does not define the exact tool life, and it is used only as an indicator, which makes it possible to compare the tool life for punches with different geometries.

\section{Optimization of the punch geometry}

The results presented in Sections 3, 4, and 5 made it possible to specify the objective functions for the punch optimization connected with:

- perforation force

$$
F_{\mathrm{P}}\left(\frac{H}{D^{2}}\right)=-1024 \ln \left(\frac{H}{D^{2}}\right)-1992.9
$$

- perforation to transverse force ratio

$$
\begin{aligned}
\frac{F_{\mathrm{P}}}{F_{\mathrm{T}}}\left(\frac{H}{D}\right)= & 907.89\left(\frac{H}{D}\right)^{3}-537.43\left(\frac{H}{D}\right)^{2} \\
& +113.15\left(\frac{H}{D}\right)-1.577
\end{aligned}
$$

- hole diameter deviation

$$
\Delta(H, D)=-12.445 H+4.2748 D
$$

Since the sharpness of the punch has a linear correlation with the punch diameter and a huge influence on the hole diameter deviations (as was proved in Sections 3 and 4), the authors were able to estimate the objective function connected with the quality of the hole (Eq. 19) by using the equation from Fig. $2 \mathrm{a}$ and treat it as a relative deviation. The goal of the tool optimization is to find the set of geometrical features for which all the objective functions reach their minimum. Based on the geometrical and technological restrictions, the depth of the spherical bowl has to be lower than $0.5 D$, which determines the range of the optimization as:

$H \in(0 ; 0.5 D) \wedge D \in(3 ; 10)$

In order to create the optimization function, three indicators of force $-x_{\mathrm{F}}$, tool life $-x_{\mathrm{L}}$, and hole quality $x_{\mathrm{Q}}$-have to be calculated based on the objective functions (Eqs. 21-23).

$x_{\mathrm{F}}=\frac{F_{\mathrm{P}}\left(\frac{H}{D^{2}}\right)}{\min \left(F_{\mathrm{P}}\left(\frac{H}{D^{2}}\right)\right)} \quad$ for $\quad 0<\frac{H}{D^{2}}<0.1 \mathrm{~mm}^{-1}$

$x_{\mathrm{L}}=\frac{\frac{F_{\mathrm{P}}}{F_{\mathrm{T}}}\left(\frac{H}{D}\right)}{\max \left(\frac{F_{\mathrm{P}}}{F_{\mathrm{T}}}\left(\frac{H}{D}\right)\right)} \quad$ for $\quad 0<\frac{H}{D}<0.5$

$x_{\mathrm{Q}}=\left\{\begin{array}{cl}1 & \text { if } \Delta \leq 0.01 D \\ 1+\Delta-0.01 D & \text { if } \Delta>0.01 D\end{array}\right.$

Based on these indicators, the optimization has the final form:

$f\left(F_{\mathrm{P}}, \frac{F_{\mathrm{P}}}{F_{\mathrm{T}}}, \Delta\right)=x_{\mathrm{F}} \cdot x_{\mathrm{L}} \cdot x_{\mathrm{Q}}$

If the optimization function $f$ reaches its minimum, it indicates that the obtained solution gives the best combination of low perforation force with maintaining a long enough tool life and the small hole diameter deviation. Also, the set of geometrical features which it represents can be considered as optimal ones. In Fig. 14a, the results for the punch geometry optimization for the punch diameters $5,6,8$, and $10 \mathrm{~mm}$ are presented. In this case, the authors used the correlations derived for a specific punch diameter from Figs. 11a and 13a. For each point which represents the minimum value of the optimization function, the proper tool was designed and presented in Fig. 14a. Since the radius of the bowl is a technological parameter, it was 

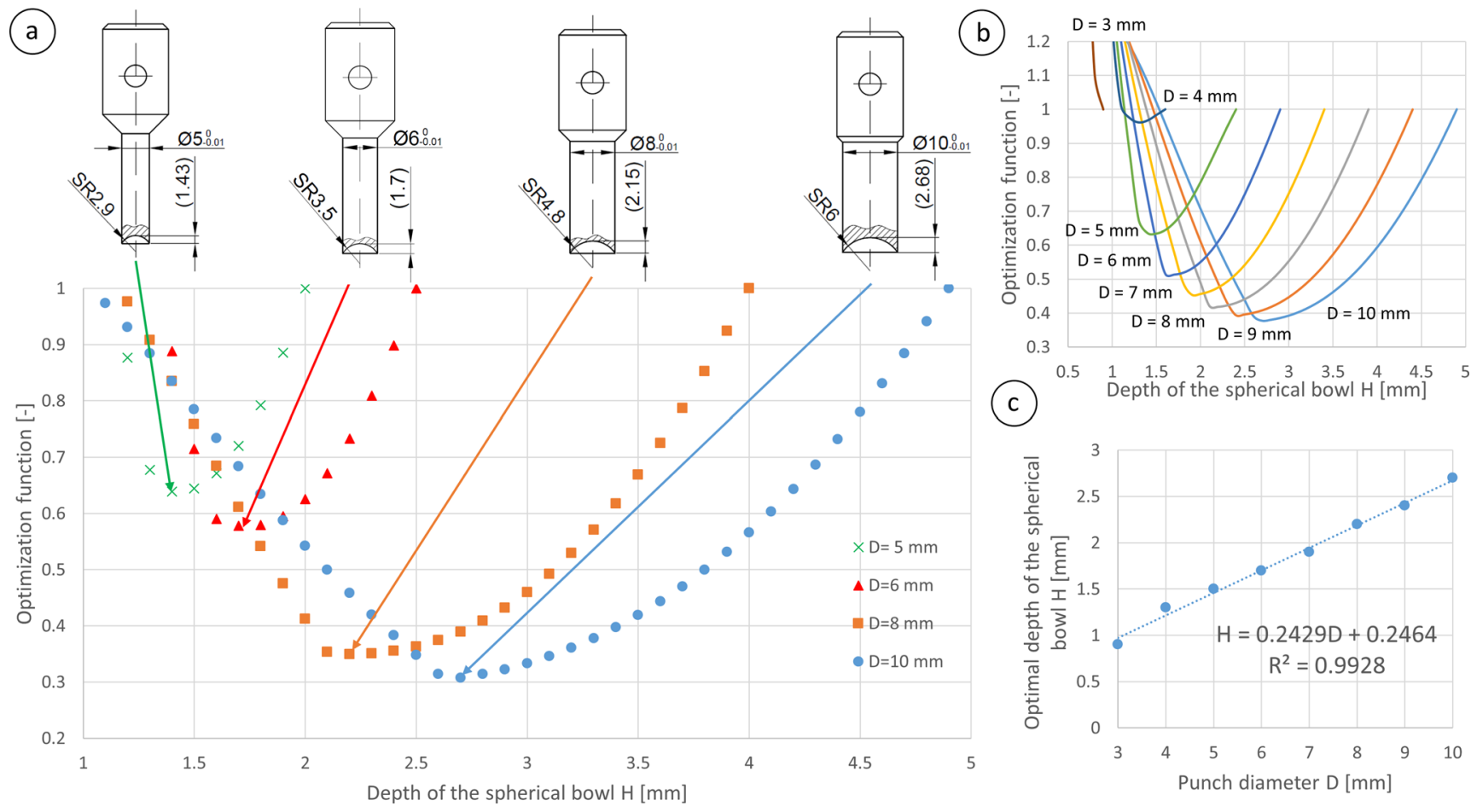

Fig. 14 a-c Optimization results and the effective geometry of a spherical bowl piercing punches for belt perforation of TFL10S belt

necessary to choose the values that provide the closest approximation to the optimal depth of the spherical bowl. In Fig. 14b, the same analysis was performed using the universal correlations from Figs. 11b and 13b, which also makes it possible to determine the optimal geometry for different punch diameters. Comparing both methods, the obtained results were identical. However, for very small punch diameters, the range of the derived model may not cover the optimal set of parameters, because the character of the process changes from punching to piercing. The correlation between the optimal depth of the spherical bowl for punching is presented in Fig. 14c.

By analyzing the solutions in the neighborhood of the optimal one, we can see that slightly increasing the perforation force and hole diameter deviations may extend the tool life and the other way around. The results of this analysis are presented in Table 5 .

Based on the results, it is visible that adding some extra restrictions to one of the indicators may lead to slightly different solutions. For some applications, the hole diameter

Table 5 Sensitivity analysis results for the neighbouring solutions to the optimal ones: $\delta$-relative error

\begin{tabular}{|c|c|c|c|c|c|c|c|c|c|}
\hline$D$ & $H$ & $x_{\mathrm{F}}$ & $x_{\mathrm{L}}$ & $x_{\mathrm{Q}}$ & $f$ & $\delta_{\mathrm{F}}$ & $\delta_{\mathrm{L}}$ & $\delta_{\mathrm{Q}}$ & $\delta_{\mathrm{f}}$ \\
\hline \multirow[t]{3}{*}{$10 \mathrm{~mm}$} & $2.6 \mathrm{~mm}$ & 1.482 & 0.204 & 1.038 & 0.314 & $1.98 \%$ & $-3.48 \%$ & $3.8 \%$ & $2.17 \%$ \\
\hline & $2.7 \mathrm{~mm}$ & 1.453 & 0.211 & 1 & 0.307 & $0 \%$ & $0 \%$ & $0 \%$ & $0 \%$ \\
\hline & $2.8 \mathrm{~mm}$ & 1.426 & 0.220 & 1 & 0.314 & $-1.90 \%$ & $4.14 \%$ & $0 \%$ & $2.16 \%$ \\
\hline \multirow[t]{3}{*}{$8 \mathrm{~mm}$} & $2.1 \mathrm{~mm}$ & 1.55 & 0.226 & 1.01 & 0.354 & $2.63 \%$ & $-2.19 \%$ & $0.8 \%$ & $1.8 \%$ \\
\hline & $2.2 \mathrm{~mm}$ & 1.51 & 0.232 & 1 & 0.350 & $0 \%$ & $0 \%$ & $0 \%$ & $0 \%$ \\
\hline & $2.3 \mathrm{~mm}$ & 1.472 & 0.238 & 1 & 0.351 & $-2.51 \%$ & $2.97 \%$ & $0 \%$ & $0.39 \%$ \\
\hline \multirow[t]{3}{*}{$6 \mathrm{~mm}$} & $1.6 \mathrm{~mm}$ & 1.66 & 0.355 & 1 & 0.591 & $5.73 \%$ & $-3.41 \%$ & $0 \%$ & $2.12 \%$ \\
\hline & $1.7 \mathrm{~mm}$ & 1.574 & 0.368 & 1 & 0.578 & $0 \%$ & $0 \%$ & $0 \%$ & $0 \%$ \\
\hline & $1.8 \mathrm{~mm}$ & 1.489 & 0.389 & 1 & 0.579 & $-5.4 \%$ & $5.91 \%$ & $0 \%$ & $0.18 \%$ \\
\hline \multirow[t]{3}{*}{$5 \mathrm{~mm}$} & $1.3 \mathrm{~mm}$ & 1.59 & 0.411 & 1.039 & 0.678 & $6.8 \%$ & $-4.44 \%$ & $3.91 \%$ & $6.05 \%$ \\
\hline & $1.4 \mathrm{~mm}$ & 1.489 & 0.43 & 1 & 0.639 & $0 \%$ & $0 \%$ & $0 \%$ & $0 \%$ \\
\hline & $1.5 \mathrm{~mm}$ & 1.392 & 0.463 & 1 & 0.645 & $-6.33 \%$ & $7.71 \%$ & $0 \%$ & $0.89 \%$ \\
\hline
\end{tabular}


deviation or the estimated tool life may be different from the extreme values. Moreover, if we are designing tools for a machine with specific drive force $F_{\mathrm{D}}$, we are able to consider not the minimal value of the force, but one which can be provided by the used drive. Because of that, the advantageous property of the optimization model is the possibility of adjustment to the specific requirements. It can be achieved by using the critical values of tool life $\left(\frac{F_{\mathrm{P}}}{F_{\mathrm{T}}}\right)_{c r}$, hole diameter deviation $\Delta_{c r}$ or the maximum drive force $F_{\mathrm{D}}$ and the expanded model is presented as Eqs. 25-27.

$$
\begin{aligned}
& x_{\mathrm{F}}=\left\{\begin{array}{cl}
1 & \text { if } F_{\mathrm{P}}\left(\frac{H}{D^{2}}\right) \leq F_{\mathrm{D}} \\
1+\frac{F_{\mathrm{P}}\left(\frac{H}{D^{2}}\right)}{F_{\mathrm{D}}} & \text { if } F_{\mathrm{P}}\left(\frac{H}{D^{2}}\right)>F_{\mathrm{D}}
\end{array}\right. \\
& x_{\mathrm{L}}=\left\{\begin{array}{cc}
1 & \text { if } \frac{F_{\mathrm{P}}}{F_{\mathrm{T}}}\left(\frac{H}{D}\right) \leq\left(\frac{F_{\mathrm{P}}}{F_{\mathrm{T}}}\right)_{c r} \\
1+\frac{\frac{F_{\mathrm{P}}}{F_{T}}\left(\frac{H}{D}\right)}{\left(\frac{F_{\mathrm{P}}}{F_{\mathrm{T}}}\right)_{c r}} & \text { if } \frac{F_{\mathrm{P}}}{F_{\mathrm{T}}}\left(\frac{H}{D}\right)>\left(\frac{F_{\mathrm{P}}}{F_{\mathrm{T}}}\right)_{c r}
\end{array}\right. \\
& x_{\mathrm{Q}}=\left\{\begin{array}{cl}
1 & \text { if } \Delta(H, D) \leq \Delta_{c r} \\
1+\Delta-\Delta_{c r} & \text { if } \Delta(H, D)>\Delta_{c r}
\end{array}\right.
\end{aligned}
$$

Additionally, by performing the sensitivity analysis, we are able to determine in which way the tolerance of machining should be directed. It may also be very useful to choose the solution from the neighboring solutions based on the technological restrictions, which are not considered in the optimization model.

\section{Summary}

The results presented in the paper show that the geometrical features of the piercing punch have a strong influence on the maximum perforation force, the tool life, and the quality of the holes. Increasing the depth of the spherical bowl punch and as a result its sharpness reduces the perforation force and provides better quality of the holes, but also shortens the tool life. In order to find the optimal geometry of the piercing punch, it is necessary to find a compromise between all these parameters. The model proposed by the authors, which was derived based on the combination of analytical calculations, FEM analyses, and a series of experimental tests, makes it possible to determine the effective geometry for the punches with different diameters. Additionally, its construction makes it possible to easily adjust it to any specific requirements, which makes it very useful for manufacturers of the perforated belts around the world. In further research, the authors plan to machine a few sets of effective tools and test them for various process parameters (punch velocity and the tool temperature) in order to improve the belt perforation process.

One of the main assets of the optimization model proposed by authors is the possibility to adjust it to the specific requirements by using some critical values of the analyzed parameters. By analyzing the solutions in the neighborhood of the optimal one, we can see that slightly increasing the perforation force and hole diameter deviations may extend the tool life and the other way around. Additionally, based on that kind of analyses, we are able to take into consideration aspects which were neglected during the modelling process, like technological issues or machining precision, which should be an important factor for industrial application of the presented research.

Open Access This article is distributed under the terms of the Creative Commons Attribution 4.0 International License (http:// creativecommons.org/licenses/by/4.0/), which permits unrestricted use, distribution, and reproduction in any medium, provided you give appropriate credit to the original author(s) and the source, provide a link to the Creative Commons license, and indicate if changes were made.

\section{References}

1. Wojtkowiak D, Talaśka K, Malujda I, Domek G (2017) Vacuum conveyor belts perforation - methods, materials and problems. Mechanik, https://doi.org/10.17814/mechanik.2017.12.192

2. Wojtkowiak D, Talaśka K, Malujda I, Domek G (2018) Estimation of the perforation force for polymer composite conveyor belts taking into consideration the shape of the piercing punch. Int $\mathbf{J}$ Adv Manuf Technol 98:9-12:2539-2561. https://doi.org/10.1007/ s00170-018-2381-3

3. Talaśka K, Wojtkowiak D (2018) Modelling a mechanical properties of the multilayer composite materials with the polyamide core. MATEC Web of Conferences 157:02052

4. Wojtkowiak D, Talaśka K, Malujda I, Domek G (2018) Analysis of the influence of the cutting edge geometry on parameters of the perforation process for conveyor and transmission belts. MATEC Web of Conferences 157:01022

5. Abele E, Fujara M (2010) Simulation-based twist drill design and geometry optimization. CIRP Annals 59:1:145-150. https://doi. org/10.1016/j.cirp.2010.03.063

6. Li A, Zhao J, Pei Z, Zhu N (2014) Simulation-based solid carbide end mill design and geometry optimization. Int J Adv Manuf Technol 71:1889-1900. https://doi.org/10.1007/s00170-014-5638-5

7. Zong WJ, Sun T, Li D, Cheng K, Liang YC (2006) FEM Optimization of tool geometry based on the machined near surface's residual stresses generated in diamond turning. $\mathrm{J}$ Mater Process Technol 180:271-278. https://doi.org/10.1016/j. jmatprotec.2006.07.004

8. Jensen MR, Damborg FF, Nielsen KB, Danckert J (1998) Optimization of the draw-die design in conventional deep-drawing in order to minimise tool wear. J Mater Process Technol 83:106114

9. Venkata Rao R, Savsani VJ (2012) Mechanical design optimization using advanced optimization techniques. Springer, London

10. Ko D-C, Kim B-M (2000) Development of an analytical scheme to predict the need for tool regrinding in shearing processes. Int $\mathrm{J}$ Machine Tools \& Manuf 40:1329-1349. https://doi.org/10.1016/ S0890-6955(99)00125-X

11. Oraby SE, Hayhurst DR (2004) Tool life determination based on the measurement of wear and tool force ratio variation. Int $\mathbf{J}$ Machine Tools \& Manuf 44:1261-1269. https://doi.org/10.1016/j. ijmachtools.2004.04.018 
12. Zhang G, Guo C (2016) Modeling flank wear progression based on cutting force and energy prediction in turning process. Procedia Manufacturing 5:536-545. https://doi.org/10.1016/j.promfg.2016. 08.044

13. Yen Y-C, Söhner J, Lilly B, Altan T (2004) Estimation of tool wear in orthogonal cutting using the finite element analysis. J Mater Process Technol 146:82-91

14. Hu Y, Yuan X, Ma G, Masen MA, Wang L (2015) Tool-life prediction under multi-cycle loading during metal forming: a feasibility study. Manuf Rev 2:28:1-7. https://doi.org/10.1051/ mfreview/201503111

15. Salonitis K, Kolios A (2014) Reliability assessment of cutting tool life based on surrogate approximation methods. Int $\mathbf{J}$ Adv Manuf Technol 71:5-8:1197-1208. https://doi.org/10.1007/ s00170-013-5560-2

16. Kovac P, Pucovsky V, Gostimirovic M, Savkovic B, Rodic D (2014) Influence of data quantity on accuracy of predictions in modelling tool life by the use of genetic algorithms. Int J Industrial Eng 21:2:14-21

17. Soares JA, Gipela ML, Lararin SF, Marcondes PVP (2013) Study of the punch-die clearance influence on the sheared edge quality of thick sheets. Int J Adv Manuf Technol 65:451-457. https://doi. org/10.1007/s00170-012-4184-2

18. Subramonian S, Altan T, Ciocirlan B, Campbell C (2013) Optimum selection of variable punch-die clearance to improve tool life in blanking non-symmetric shapes. Int J Machine Tools Manuf 75:63-71

19. Lo S-P, Chang D-Y, Lin Y-Y (2010) Relationship between the Punch-Die clearance and shearing quality of progressive shearing die. Mat Manuf Process 25:786-792. https://doi.org/10.1080/ 10426910903447295

20. Ueda T, lizuka T, Enoki S (2016) FEM analysis of punchingprocess in consideration of micro die wear. MATEC Web of Conferences 80:15006

21. Esmaeilpour R, Kim H, Park T, Pourboghrat F, Xu Z, Mohammed B, Abu-Farha F (2018) Calibration of barlat Yld2004-18P yield function using CPFEM and 3D RVE for the simulation of single point incremental forming (SPIF) of 7075-O aluminum sheet. Int J Mech Sci 145:24-41. https://doi.org/10.1016/J.IJMECSCI.2018. 05.015

22. Esmaeilpour R, Kim H, Park T, Pourboghrat F, Mohammed B (2017) Comparison of 3D yield functions for finite element simulation of single point incremental forming (SPIF) of aluminum 7075. Int J Mech Sci 133:544-554. https://doi.org/10. 1016/j.ijmecsci.2017.09.019

23. Holmberg S, Persson K, Petersson H (1999) Nonlinear mechanical behaviour and analysis of wood and fibre materials. Comput and Struct 72:459-480
24. Pal B, Haseebuddin MR (2012) Analytical estimation of elastic properties of polypropylene fiber matrix composite by finite element analysis. Adv in Mat Phys and Chem 2:23-30

25. Shetty N, Shahabaz SM, Sharma SS, Shetty SD (2017) A review on finite element method for machining of composite materials. Composite Struct 176:790-802

26. Dandekar CR, Shin YC (2012) Modeling of machining of composite materials: a review. Int J Mach Tools \& Manuf 57:102121

27. Garcia JJ, Rangel C, Ghavami K (2012) Experiments with rings to determine the anisotropic elastic constants of bamboo. Constr and Build Mat 31:52-57

28. Vasic S, Smith I, Landis E (2005) Finite element techniques and models for wood fracture mechanics. Wood Sci Technol 39:3-17

29. Torres LA, Ghavami K, Garcia JJ (2007) A transversely isotropic law for the determination of the circumferential young's modulus of bamboo with diametric compression tests. Latin Americ App Res 37:255-260

30. Dandekar CR, Shin YC (2009) Multi-step 3D finite element modeling of subsurface damage in machining particulate reinforced metal matrix composites. Compos Part A 40(8):1231-1239

31. Zhou L, Huang ST, Wang D, Yu XL (2011) Finite element and experimental studies of the cutting process of $\mathrm{SiCp} / \mathrm{Al}$ composites with PCD tools. Int J of Adv Manuf Technol 52:619-626

32. Ventura CEH, Hassui A (2013) Evaluation of static cutting forces and tool wear in HSM process applied to pocket milling. Int J Adv Manuf Technol 65:1681-1689

33. Voss BM, Pereira MP, Rolfe BF, Doolan MC (2017) Using stamping punch force variation for the identification of changes in lubrication and wear mechanism. IOP Conf Series: Journal of Physics: Conf Series 896:012028

34. Choudhury SK, Kishore KK (2000) Tool wear measurement in turning using force ratio. Int J Mach Tools Manuf 40:899-909

35. Akyürek F, Yaman K, Tekiner Z (2017) An ExperimentalWork on ToolWear affected by die clearance and punch hardness. Arab J Sci Eng 42:4683-4692

36. Gouarir A, Martínez-Arellano G, Terrazas G, Benardos P, Ratchev S (2018) In-process tool wear prediction system based on machine learning techniques and force analysis. Procedia CIRP 77:501504

37. Siddhpura A, Paurobally R (2012) A study of the effects of friction on flank wear and the role of friction in tool wear monitoring. Australian J Mech Eng 10:141-156. https://doi.org/ 10.7158/M12-027.2012.10.2

Publisher's note Springer Nature remains neutral with regard to jurisdictional claims in published maps and institutional affiliations. 